\title{
MAMMALIAN NREM AND REM SLEEP. WHY, HOW AND WHEN
}

Rubén Víctor Rial*1, Mourad Akaârir ${ }^{1,3}$, Francesca Canellas ${ }^{1,2}$, Antoni

Gamundí $^{1}$, Aida Martín Reina ${ }^{1}$, Pere Barceló ${ }^{1}$, José A. Rubiño ${ }^{1}$, M. Cristina Nicolau ${ }^{1}$

${ }^{1}$ Laboratori de Neurofisiologia del Son i dels Ritmes Biològics

Departament de Biologia

Universitat de les Illes Balears, IUNICS, IDISPA

Palma de Mallorca (Illes Balears, España)

${ }^{2}$ Hospital Son Espases, Servei de Psiquiatria

Palma de Mallorca (Illes Balears, España)

${ }^{3}$ Clínica Juaneda, Unidad de sueño

Palma de Mallorca. (Illes Balears, España)

Corresponding author:

RV. Rial

Laboratori de Neurofisiologia del Son i dels Ritmes Biològics

Departament de Biologia

Universitat de les Illes Balears.

Ctra Valldemossa, $\mathrm{km} \mathrm{7.5,}$

07122, Palma de Mallorca (Illes Balears, España)

Email: rvrial@uib.es Phone: +34971173147_ Fax: +34971173184

Acknowledgements:

This research did not receive any specific grant from funding agencies in the public, commercial, or not-for-profit sectors 
The authors are gratefully indebted to Mrs. Kendra Moloney for reviewing the English language of this article

This review has been made under the direction of R.V. Rial. All remaining authors have made a substantial, direct and intellectual contribution to the work and approved it for publication. 


\begin{abstract}
Mammalian NREM and REM sleep. Why, how, and when
\end{abstract}

Three types of wakefulness appeared along the vertebrate's phylogeny and ontogeny: spinal-rhombencephalic in fish, brainstem-diencephalic in reptiles and cortical in mammals, in which the paralyzed spinal-rhombencephalic wake and the brainstemdiencephalic wake remain as REMS and NREMS

The spinal-rhombencephalic and cortical types of wake are inherently anti-homeostatic. Animals must forage, reproduce, and survive to predation disregarding the environmental circumstances, hence temporarily forgetting the homeostatic regulation. After fulfilling the vital functions, the brainstem-diencephalic wake recovers the homeostatic control.

The phasic signs of REMS are adaptive in immature mammals, serving for demanding heat, milk and defense to their mother. These advantages outweigh the REMS' poikilostasis in infants. The adults' poikilostasis of REMS is harmless in thermoneutral environments but is mal-adaptive in aquatic environments in which REMS is reduced or even disappears. These exceptions explain the anomalous examples of REMS.

An on-off hypothalamic switch homeostatically regulates the entrance and exit from REMS. Furthermore, the vital phasic signs of REMS depend on a second pontine proportional homeostatic control. Altogether, they regulate the expression of REMS.

Keywords: Evolution of sleep; Nocturnal bottleneck; Origin of NREM sleep; Origin of REM sleep 


\section{Introduction}

Sleep seems to be universal in animals. In behavioral terms, it is often diagnosed attending to seven signs: 1) quiescence, 2) reversibility, 3) preferred sleeping places, 4) stereotyped body positions, 5) raised sensory thresholds, 6) circadian organization and 7) homeostatic regulation (Piéron, 1912; Flanigan et al., 1973; Bruce Durie, 1981; Borbély, 1982, 2016; García-García, \& Drucker-Colín, 1999). Sleep also may be diagnosed by recording the electrophysiological variables of sleeping subjects. In this case, the record receives the name of polysomnography (PSG), with recordings of brain activity (EEG), muscular activity (EMG), eye movements (EOG) and, eventually, other signs: heart rate, respiration, Body Temperature (BT) (central and peripheral) etc.

The polygraphic sleep, defined only in homeothermic vertebrates, revealed the existence of two sleep states in mammals and birds: non-REM sleep (NREMS) and REM sleep (REMS). The present review, however, will only deal with the mammalian sleep. Some of the answers we propose here to explain the origin of the mammalian NREMS and REMS cannot be applied to birds. Nevertheless, when convenient, a few mentions will be made to avian sleep.

The functional difference between NREMS and REMS is so important that many authors believe that the two types of sleep are independent states of conscience, which contributes to the mysterious nature of sleep. Nevertheless, our group proposed, several years ago, that the evolution of the reptilian wake gave origin to mammalian sleep, including the cycles of NREMS and REMS (Rial et al., 1993, 2007a, 2010). Briefly, reptiles spend their activity time in two main states: 1) heliothermictigmothermic thermoregulatory behavior, that in the following will be called "Basking Behavior" (BB) and 2) a set of foraging, reproductive, defensive and agonistic 
behaviors that in the following will be called "Goal Directed Behaviors" (GDB). According to our proposal, BB and GDB were the antecessors of NREMS and REMS, respectively.

As reptiles cannot choose the thermal environment in which food, predators, prey, rivals and reproductive partners would be found, they abandon the behavioral thermoregulation during GDB until arriving to a low body temperature threshold. Then, they must return either to bask again, or to their shelter in which they may rest waiting for environmental improvements. Obviously, BB is inoperative under the cover of the shelter. Then, according to the $\mathrm{Q}_{10}$ law, their $\mathrm{BT}$ and metabolic rate will drop (Bradshaw \& Main, 1968; Brattstrom, 1971; Christian and Weavers 1996). The $\mathrm{Q}_{10}$ index represents the ratio of the velocity of a given physiological process versus the same process at a temperature $10{ }^{\circ} \mathrm{C}$ lower. Typical values of the $\mathrm{Q}_{10}$ oscillate around 2 , meaning that every $10{ }^{\circ} \mathrm{C}$ descent in BT halves the speed of the process under consideration (Bennett, 2010).

The thermal inertia of big sized reptiles allows them to maintain a relatively high BT when the environment is favorable. Instead, small sized species with a low thermal inertia - those that gave origin to mammals - select microenvironments where they may shuttle between BB and GDB in several daily cycles that may persist until dusk, where they are forced to rest with a low BT and reduced metabolism (Stanton-Jones, et al., 2018; Basson et al, 2017; Rowe et al., 2020; Souza et al., 2020). Nevertheless, in nonfavorable environments, reptiles can rest passively in their shelter during several days and even weeks without harm (Rose, 1981; Huey, 1982).

The control of the transitions between reptilian BB and GDB involves two setpoints. An upper set point determines the end of BB and the beginning of GDB, while a lower set point controls the suspension of GDB and the return to BB (Huey, 
1982; Huey and Slatkin, 1976; Firth and Turner, 1982; Foa et al., 1992; Rivera-Vélez \& Lewis, 1994; Tosini et al., 1995). Noteworthy, these set points are severely impaired after specific hypothalamic lesions (Kluger et al., 1973; Berk \& Heath, 1976; Bicego \& Branco, 2002; Bicego et al, 2007; Liu et al, 2006; Piercy et al., 2015). Altogether, the two set points drive the behavioral regulation of BT in function of temperature, rainfall, solar radiation, humidity, season, time of day, predatory risk, body size, sex, reproductive state, energetic reserves, etc. (Rose, 1981; Lister \& Aguayo, 1992; Merker, \& Nagy, 1984) factors that may even cause changes in the hypothalamic set points (Garrick, 1979; Withers, \& Campbell, 1985; Tosini and Avery, 1993). Taking, for example, the lizard Ameiva exsul ( $\sim 50 \mathrm{~g}$ body weight), the average heating (BB) and foraging (GDB) durations were $\sim 17.9$ and $\sim 60 \mathrm{~min}$, respectively (Rivera-Vélez \& Lewis,1994), while in Podarcis muralis ( 2.5-7.0 g body weight) the mean basking duration ranged from $\sim 2.4$ to $\sim 3$ min (Tosini et al., 1995) and the following foraging time oscillates between $\sim 3.14$ and $\sim 9.7$ min, respectively (Tosini \& Avery, 1996).

Remarkably, the two reptilian states are compulsory to maintain an active life: BB is needed to raise BT for a physiologically efficient activity and GDB is needed for life sustaining activities (Mukherjee et al, 2018; Rose, 1981; Huey, 1982; Karasov \& Anderson, 1984; Pietruszka 1986).

2. The birth of the mammalian sleep.

In the Cretaceous-Paleogene boundary, about $66 \mathrm{Mya}$, some individuals of the primitive reptilian stock began to develop incipient endothermy by increasing the energetic metabolism. In this way, they were able to progressively extend their activity, first to twilight hours and successively to the entire nighttime. However, attempting to attain the maximal visual sensitivity in the new scotopic environment, they abandoned the filters protecting the eyes against the dangerous diurnal light. This process is known 
as the Nocturnal Evolutionary Bottleneck (Walls, 1942) and is currently considered responsible of the evolution, from diurnal reptiles, to the first mammals, that began to be nocturnal and, in most extant species, continue being so (Gerkema et al., 2013; Heesy \& Hall, 2010; Wu et al, 2017). Obviously, the abandon of the visual filters exposed those pre-mammals to the dangers of diurnal bright light. Thus, to avoid becoming blind by accidental exposure to daylight, they were forced to remain paralyzed in lightproof burrows during light time. In conclusion, their chronotype was inverted, from being strictly diurnal, to rest with closed eyes during light time and becoming active only during dark time. This was how the mammalian sleep was born: a state of behavioral paralysis with closed eyes (Rial et al., 2019).

Nevertheless, despite the suspension of behavioral output during light time, those early mammals conserved the cyclic structure of their previous diurnal wakefulness. Indeed, the paralyzed BB became NREMS while the also paralyzed GDB became REMS. This was how the two main phases of the mammalian sleep appeared. Excepting the suppression of the motor output, the cyclic organization of BB-GDB and NREMS-REMS are almost identical. Among other factors, both depend on hypothalamic control and on most thermal factors. We saw that the thermoregulation is disregarded during the reptilian GDB (Nicolau et al, 2000; Rial et al., 2007a; 2010; 2019) but also during the mammalian REMS (Parmeggiani, 2011) and many authors observed similar thermal limits for the transitions between NREMS and REMS (Szymusiak and Satinoff, 1981; Charles et al., 1980; Muzet et al., 1983; Jürgen, 1980; Whitten et al., 2009). Moreover, the increases in environmental temperature toward the highest end of the thermoneutral zone preferentially increases REMS over NREMS (Komagata et al., 2019; Szymusiak et al., 1980; Muzet et al., 1983) a result that fits quite well with the homology we propose between the reptilian BB-GDB and the 
mammalian NREMS-REMS. Indeed, increasing the environmental temperature must reduce the time spent by reptiles in BB (NREMS) and must allow more free time for GDB (REMS).

The present report will add reasonable evidence for the hypothesis described in the previous paragraph. Nevertheless, our main goal aims at explaining the origin and the persistence, in modern mammals, of the tonic and phasic traits of REMS. We will propose that the constellation of REMS signs is the result of the interaction between the anatomic and functional activity of different sub-telencephalic and telencephalic brain regions.

As a departure point, we will take the words of Crick and Mitchison (1983): 'Any purely psychological theory is hard pressed to explain the large amount of REM in the womb and any purely developmental theory must account for the quite appreciable amount of sleep in adult life'.

We will begin by defining wakefulness: it is a behavioral state with capability of perceiving environmental stimuli and responding to them with adaptive behavior. This definition will serve to defend the existence of several types of wakefulness in function of the ontogenetic and phylogenetic development of the brain. We will propose, first, the existence of a primary spinal-rhombencephalic wakefulness that can be found in fish, in all vertebrate embryos and in mammalian REMS. The existence of a primitive form of spinal-rhombencephalic wake has already been proposed (Corner and Schenk, 2015). However, we expand their proposal adding a second brainstem-diencephalic wakefulness in poikilothermic and mammalian vertebrates, to end with a third wakefulness, the cortical wakefulness, only present in mammals. The existence of three different types of wakefulness along the vertebrate's phylogeny and ontogeny will serve 
to understand the first part of Crick and Mitchison's observation, namely, why REMS is so abundant in newborns.

3. The development of wakefulness

In order to understand the evolution of the different types of wakefulness we must look at the progressive neuroanatomical development of the vertebrate brain in caudalrostral direction. The mammalian embryos begin developing the spinal cord, which is followed by the successive development of medulla, pons, midbrain, diencephalon, to end with the full development of the telencephalic cortex (Joseph, 2000). Obviously, the functional maturation follows the same caudal-rostral order (Kadić \& Predojević, 2012) and the same embryonic stages of brain development may be observed in the vertebrate's phylogenesis. For instance, the telencephalic development is practically zero in prochordates (Lacalli, 2001) but successively increases in size and complexity in fish, amphibians, reptiles and mammals (Butler et al., 2011; Butler and Hodos 2005).

\subsection{Spinal wake}

The isolated spinal cord of fish can produce rhythmic swimming movements, identical to intact fish, with complete intersegmental coordination (Cohen and Wallén, 1980; Grillner and Wallen, 2002; Cangiano \& Grillner, 2003; Sigvardt, 1989). Similar observations have been reported in tadpoles (Stehouwer and Farel, 1980, 1981; Corner \& Crain 1965; Corner, 1964), in reptiles (Srivastava, 1992; Kusuma \& Ten Donkelaar, 1980) and even in adult mammals, in which ambulatory movements and many other well-coordinated reflexes have been repeatedly reported in spinally transected animals (Sherrington 1910, cited by Hart, 1971; Handa et al., 1986; Sigvardt, 1989). 
In ontogenetic terms, the spinally controlled jerks are the earliest signs of spontaneous activity in mammalian embryos. They depend on the random firing of spinal motor neurons (Blumberg et al., 1994; Corner \& Schenck, 2015) but are rapidly transformed into well-coordinated sensory evoked spinal reflexes, that is, in signs of spinal wake, with capability for elaborating adaptive responses to environmental stimuli (Suzue \& Shinoda., 1999; Saint-Amant \& Drapeau, 1998; Tadros et al., 2015; Fitzgerald, 2005; de Vries et al. 1985; Humphrey, 1964; Oberlander et al., 2002; Corner, 1985). Therefore, we see that, in absence of the anterior parts of the brain, be it due to low development, or to experimental procedures, all vertebrates show spinal capacity to perceive and react to incoming sensory stimuli with adaptive responses or, in other words, they show spinal wake. These activities were named as "Motor Primitives" (Dominici et al., 2011) and "Rapid Body Movements (Corner \& Schenck, 2015) but also GDB (Rial et al, 2010; 2019).

\subsection{Rhombencephalic wake}

The rhombencephalon, together with medullar and spinal regions, is responsible for basic life sustaining functions, including respiratory control (Alheid et al 2004; Chatonnet et al., 2002), cardiocirculatory activity (Hoffmann \& de Souza, 1982; SévozCouche et al., 2003), digestive reflexes (mastication, swallowing, retching) (Turman et al., 2001; Amri \& Car, 1988; Lu et al., 1997) and even facial expressions (Auclair et al., 1996; Huang et al., 2009), including, ocular movements, e.g., the gaze following behavior (Cohen, 1974; Verzijl et al., 2003; Dos Santos et al., 2006) and other sensorymotor responses. Interestingly, it has been found that, after categorizing the significance (positive or negative) of a given visual stimulus, the motor responses of larval zebrafish are activated through the contralateral or ipsilateral tecto-bulbar tracts, so coordinating 
the visual tracking and mobility, toward or away, respectively, from the stimulus, (Helmbrecht et al., 2018).

Undoubtedly, the described sensory-motor responses should be interpreted as signs of primitive rhombencephalic wake. An animal capable of perceiving a visual object and deciding to escape from, or follow it, must be awake. Therefore, the rhombencephalon of primitive vertebrates, but also of undeveloped embryos is capable, by itself, of actively controlling alternative periods of muscular atonia (Corner, 1977; Siegel, 2011; Valatx et al., 1964; Hobson, 2009) interspersed with episodes of muscular activity in the form of sensory evoked startles and pursuit/escape behaviors, the last ones being the basic components of the fight-fright-flight behavioral patterns (Bullock, 1984; Corner \& Schenck, 2015).

The main conclusion of previous paragraphs is that an undisputable evidence exists showing that primitive vertebrates and mammalian embryos possess a kind of simplified rhombencephalic wake. After an almost complete block of the motor output this wake - which we will name as REM wake - was transformed into the REMS of adult mammals. In the next paragraph we will see that the phasic signs of REMS possess a high adaptive value. This may be the first answer to the up to now unresolved question of why newborn mammals have REMS.

\subsection{The adaptive significance of the phasic signs of REMS}

Many authors recognized that the muscular twitches and jerks observed in REMS are the remainder of incomplete startles and orienting reflexes (Emde and Metcalf, 1968; Wu et al. 1989; Wu and Siegel, 1990; Blumberg and Stolba, 1996; Blumberg and Lucas, 1994; Morrison, 2005; Jha et al., 2005). i.e., the result of a partial obliteration of GDB. The twitches and jerks are astoundingly frequent in rat pups, with an estimated frequency of tens of thousands per day (Blumberg and Seelke 2010; 
Blumberg et al., 2013). Thus, an important question is why animals developed a highly efficient system to block skeletal motor neurons during REMS and, at the same time, the system drains such high amounts of incomplete movements in REM sleeping newborns (Roffwarg et al., 1966).

The neural mechanism responsible for the tonic REMS immobility depends on GABAergic and glycinergic neurons that inhibit the spinal motoneurons (Sastre et al., 1981; Soja et al., 1987; Morales et al., 2006; Vetrivelan et al., 2009). However, the inhibitory drive progressively fades because of the increased activity of excitatory glutamatergic neurons located in the medial medulla that progressively allow the disinhibition of motoneurons and the expression of the muscular twitches and jerks (Brooks \& Peever, 2016). As a result, the phasic signs of REMS could never be considered random byproducts of the state, but the result of a well-regulated balance between the GABAergic-glycinergic inhibition and the glutamatergic stimulation of skeletal motoneurons (Brooks \& Peever, 2016).

The production of such enormous amounts of twitches and jerks should be rather costly, and it can be only understood if the pups obtain some compensatory advantage. Many authors consider that they serve for sensorimotor maturation (Tiriac et al., 2015; Khazipov et al., 2004; Petersson et al., 2003; Roffwarg et al., 1966; Mirmiran et al., 2003; Corner \& Schenk, 2015; Blumberg et al, 2013) because 1) an inverse correlation exists between the total REMS time and the brain maturity and 2) because the suppression of REMS in immatures provoke deficits in the brain maturational processes. In our opinion, these arguments are weak: 1) because correlations should be never used to affirm causal relationships and the correlation between total REM time and brain maturation may be more parsimoniously explained as an epiphenomena of brain growth, and 2) because suppressing REMS in infants is only one among the 
immense number of ways to interfere with the delicate machinery of brain development (Gamundí et al., 2005).

In contrast, we will defend that the twitches and jerks are adaptive by themselves. We do not want to completely reject the idea that the REM calls, jerks and twitches may contribute to improve the muscular capabilities of adult mammals (see Dattilo et al., 2012; Blumberg et al., 2013) but we will add an advantage that, being known since long, it has never been considered. Unattended sleeping newborn rats exposed to low temperatures respond first, by increasing the Brown Adipose Thermogenesis, but after further temperature drops, the production of metabolic heat may be insufficient and the pups risk becoming cool (Blumberg and Stolba, 1996). The easiest way to avoid hypothermia lies in obtaining heat from the dam. It has been found that isolated and cooled rat pups begin emitting $22 \mathrm{kHz}$ ultrasound vocalizations that are effective stimuli to induce maternal retrieval (Allin \& Banks, 1972; Curry et al., 2013). However, if BT continues plunging, the vocalizations are substituted by an increased rate of twitches and jerks. Therefore, REM sleeping rat pups may show a well-regulated capacity for perceiving and reacting to environmental factors Therefore, is evident that they possess a primary form of wake, controlled from rhombencephalic regions, i.e. REMW.

So, the vocalizations of isolated, cooled or hungry pups and the production of twitches and jerks serve for communicating negative emotional states to the mother and for demanding defense, heat and/or milk (Wöhr et al., 2010; Schwarting \& Wöhr, 2018). It can be furtherly reasoned that the frequency of twitches, jerks and ultrasonic vocalizations should be proportional to the degree of cooling/hunger, which should progressively increase in proportion to the duration of the REMW episode and the consequent time-dependent descent in brain temperature, as predicted by the regulatory 
mechanisms described by Brooks \& Peever (2016). In summary, the calls, jerks and twitches are regulated responses to isolation, cooling and hunger and are controlled by spinal and rhombencephalic activity (Brudzynski, 2013; Brudzynski \& Fletcher, 2010; Silkstone \& Brudzynski, 2019).

The dams respond to the calls by retrieving the pups and crouching over them. Then, the ventral stimulation, received, either from twitching or sucking pups, elicits immobility in the dam (Stern and Johnson, 1990; Stern, 1991; Stern et al., 1992; Pedersen, 1997; Morgan et al., 1992; Lonstein et al., 1998). In contrast, dams cease responding when pups are inactive, or incapable of rooting or suckling, that is, dams readily respond to active cooled and/or hungry pups - in REMW - but are less interested in warm, well-fed, and quietly sleeping - in NREMS - pups. Moreover, inter-pup competition has been found in many altricial species (Gilbert, 1995; Bautista et al., 2008; Madden et al., 2009; Coureaud et al., 2000; Drummond et al., 2000, for milk) and (Alberts, 2007; Bautista et al., 2003; Gilbert 2010 for heat). Indeed, huddling pups frequently fight for the nipples and shuttle between the border and the core of the huddle to increase the gain of heat by a tigmothermic procedure - gaining heat from the warm skin of the mother, so minimizing the metabolic expenditures (Alberts, 1978). Altogether, the eye movements, added with the full set of calls, muscular twitches and jerks, may be an example of evolutionary exaptation (Gould \& Vrba 1982). The original pursuit movements, together with the fight, fright, and fly reflexes began as useful responses for foraging or to escape from unexpected, dangerous environmental stimuli, but finished as signs for demanding help to the mother. But the most important point is that the myoclonic twitches, jerks and calls may have an immense survival value for immature rat pups, much higher than a complete atonia and the currently believed maturational sensorimotor development. 
Interestingly, similar haptic and vocal activities have been reported for motherinfant communication in animals showing maternal care, e.g., mammals, including humans (Stern, 1997; Hofer, 2002; Swain et al., 2007), reptiles (Herzog \& Burghardt, 1977; Vergne \& Mathevon, 2008; Vergne et al.,2009; Vergne et al.,2012; Sicuro et al.,2013; Ferrara et al.,2013) and birds (Brua, 1996; Evans, 1990, 1994; Gräns \& Altimiras, 2007; Nichelmann \& Tzschentke, 1997; Rumpf \& Tzschentke 2010). In every case, the mother readily responds by retrieving and covering the pups or eggs and protecting them from predation, hunger, or cooling. The wide distribution of these activities suggests an old phylogenetic origin and confirm their high adaptive significance (Bass and Chagnaud 2012), exceedingly surpassing the current explanation, the sensorimotor maturational hypothesis.

\subsection{Brainstem-diencephalic wakefulness}

In phylogenetic terms, the participation of diencephalic structures in the production of a second type of wakefulness is evident in the thermoregulatory behavior. The hypothalamic controlled capacity for selecting the preferred environmental temperature is widespread in vertebrates (Crawshaw et al., 1981), having been observed in fish (Reynolds et al., 1976; Nelson \& Prosser, 1979; Matern et al., 2000; Beitinger \& Magnuson, 1979; Newell \& Quinn, 2005; Golovanov, 2006; Reynolds \& Casterlin, 1979), amphibia (Corner, 1964; Casterlin \& Reynolds, 1977, 1980), reptiles (Kluger et al., 1973; Berk \& Heath, 1976; Nelson et al., 1984) and mammals (Schradin et al, 2007; Terrien et al, 2011) including wakeful human adults (Shim \& Jeong, 2011) but also during NREMS (Frank et al, 1999; Parmeggiani, 2011).

Importantly, the behavioral thermoregulation of poikilothermic vertebrates only is possible during wake. Indeed, the behavioral control only is possible in behaving animals and remains inactive during behavioral rest, not only in anamniotes (fish and 
amphibians) but, importantly, in poikilothermic amniotes - reptiles - in which the dependence of external heat sources for body warming is, in practice, absolute.

We are aware of some reports affirming the existence of NREMS and REMS during nighttime in supposedly sleeping lizards (Shein-Idelson et al., 2016; Libourel et al., 2018). However, we should remark, first, that these proposals were seriously criticized in posterior reports (Libourel \& Barrillot, 2020). We should add that the existence of true sleep should be definitively discarded in poikilothermic vertebrates after understanding that the so-called reptilian nocturnal sleep is only a passive hypothermic state. Indeed, sleep is the result of complex and active processes, and the old belief that sleep results from reduced sensory input and/or low brain activity has been discarded since long (Dement, 2017).

The mammalian brainstem is capable, by itself, of controlling, not only the basic homeostatic functions, but also many complex behavioral patterns during wake. For example, substantial behavioral capacity has been demonstrated in animals after experimental decortication. Chronic mesencephalic rats and cats show well-coordinated postural and locomotor capacities, normal grooming, and complete defensive responses. (Woods 1964; Lovick; 1973; Berntson and Micco, 1976; Humphries et al., 2005; Blumberg \& Plumeau, 2016). Furthermore, human fetuses in late gestational ages when, presumably, their cortex is still undeveloped - respond to stimuli perceived through the abdominal wall of the mother. Fetuses can even discriminate the mother's voice from other sounds, showing variable responses to acoustic stimuli, meaning that their auditory system, the mesencephalic posterior colliculi, isthmus and rhombencephalic cochlear nuclei, are functional (Sohmer \& Freeman, 1995; Kisilevsky et al., 1998; Grimwade et al., 1970; Lecanuet \& Schaal, 1996). Moreover, many sensory and motor manifestations that are active in premature and at term human newborns, 
disappear after a few weeks, to return after a while (Bever, 1982; Strauss \& Stavy, 1982; Muir, \& Hains, 2004). In every case, these "U" shaped developmental processes have been satisfactorily explained as dependent, first from spinal and brainstem activity and, after further maturation - the second branch of the " $U$ " process - from higher brain structures (Jane et al., 1972; Berntson \& Micco, 1976; Morton \& Johnson, 1991; Muir \& Hains, 2004; Field et al., 1980; Johnson, 2001; Atkinson et al., 1984; Richards, 2001; Dubowitz et al.,1986; Khodadadifar, 2015).

The existence of brainstem-diencephalic wake receives further support from the behavior of anencephalic human newborns. They may show normal sleep-wake cycles and, while awake, can perform elaborate behavioral patterns, including responses to noxious stimuli, feeding and respiratory reflexes and even social interactions involving eye movements and facial expressions (Francis et al., 1984). The complexity of their behavior arrives to the point that parents often mistakenly believed that their child was normal during the first or second month of life (Halsey et al., 1968; Hoffman \& Liss, 1969; Shewmon. 1988; Pant et al., 2010).

Altogether, the facts described in previous paragraphs show that sub-mammalian vertebrates and immature mammals have two types of wakefulness, the already described spinal-rhombencephalic wake and the brainstem-diencephalic wake.

\subsection{Cortical wakefulness}

We should describe here the existence and the main traits of cortical wakefulness. However, the intervention of the cortex in the sensory-motor control of mammalian wake is evident and undisputed. For the sake of brevity, we will refer to the abundant literature describing the neuroanatomical control and the features of the cortical wake (see, for instance, Cirelli \& Tononi, 2015; Schwartz \& Roth, 2008; Berridge et al., 2012; Wright et al., 2012; Brown \& McKenna, 2015). Of course, the 
cortical wake is the result of a complete integration between the spinalrhombencephalic, mesencephalic and diencephalic types of wakefulness. Thus, we will take for granted the existence of cortical wakefulness and the associated neural structures.

\subsection{Phylogenesis and ontogenesis of wakefulness, NREM and REM sleep}

It is evident that the ontogenesis of behavioral states repeats the phylogenetic sequence: mammalian embryos begin showing cycles of spinal-rhombencephalic wake, with phasic-tonic signs that, when manifested during REMS, work as a link for communication between mother and embryo and/or newborn. In successive developmental stages, the brainstem-diencephalic wake is the main wakeful state providing homeostatic control in poikilothermic vertebrates but also in mature mammals during NREMS and restful waking. The series ends with the mammalian cortical wake, in which the rhombencephalic, the brainstem-diencephalic and the cortical wake are fused. However, when the cortical wake is suspended, the cycles of spinal-rhombencephalic/brainstem-diencephalic wake appear in newborns but also in the NREMS-REMS cycles of adult mammals with paralyzed motor output because of the inhibitory command of the substantia nigra during NREMS (Liu et al 2020) and the already described glycinergic-GABAergic inhibition of motor neurons during REMS. Importantly, the existence of two independent mechanisms to block the motor output during REMS and NREMS add strength to the independent origin and the successive expression of the different types of wake that, only during cortical activity can be simultaneously expressed, so contributing to full wakefulness.

Of course, we are unable to define clear-cut neuroanatomical boundaries between the different types of wake. Many authors expressed concern about the naïve assumption that the phylogenetic development of the brain would be explained as 
having occurred with the addition of successive neuroanatomical layers, in the form of a multi-tiered cake. Indeed, each one of the different types of wake is the result of a continuous process involving the entire brain and expressed in each phylogenetic and/or ontogenetic stage (Braun, 2000; Soussignan, 2003). For instance, the spinal rhombencephalic also implies the activity of upper brain regions as it is shown, for instance, with the cortical EEG arousal that appears in mammals during REMS. Nevertheless, the available evidence shows that the executive control of wake successively ascends from lower to upper brain regions, following the ontogenetic/phylogenetic neuroanatomical and functional development of the brain (Joseph, 2000; Kadić \& Predojević, 2012). Indeed, each of the primitive forms of waking is sufficient, by itself, for an effective and adaptive control of the whole behavior. However, the different types of wake are successively nested in the phylogenetic-developmental progression. Of course, the cortical mammalian waking makes extensive use of the waking capabilities of the entire nervous system, that only appear as independent stages in early developmental stages or during NREMS and REMS.

As an interim conclusion, we will remark first, that the spinal-rhombencephalic and brainstem-diencephalic stages of wakefulness are unavoidable and never fail to appear in all vertebrates, without exception. All vertebrates must surpass them in successive embryonary stages, and all continue to possess vital functions in adults to control, as described, many GDB patterns and the bodily homeostasis. However, we will see that the obligatory character of the REMW may seemingly disappear, for example, in some primitive mammals and in marine mammals. We will maintain that even in these cases, REMW continue existing.

4. EEG and behavioral states in vertebrates 
While the EEG is the most important sign to define the electrographic wake and sleep of mammals, it has been much less studied in non-mammals. As a result, some EEG traits remain poorly understood in them.

The main EEG signatures used to define the electrographic wake and sleep are amplitude, frequency, temporal characteristics, and several isolated EEG graphisms. The alpha, beta, delta, theta and gamma frequency bands of the EEG have been widely used to study the human wake-sleep states and, by extension, the mammalian sleep. In addition, the sigma spindles, PGO potentials, $\mathrm{K}$ complexes and high voltage isolated spikes are frequently used graphisms to further differentiate states. The following paragraphs will analyze the relationships between EEG and behavioral states in the whole vertebrate class.

The delta EEG, also called Slow Wave EEG (SWEEG), with high amplitude, low frequency waves is an essential, but not exclusive sign of NREMS. Indeed, SWEEG has been described, not only in NREM sleeping mammals, but also in waking altricial newborns (Emde and Metcalf, 1968; Vecchierini et al., 2007; André et al., 2010) in REM sleeping platypus (Siegel et al., 1999) and even in REM sleeping humans (Bernardi et al., 2019). Furtherly, high power SWEEG has been recorded after the administration of scopolamine, an anticholinergic drug and results in seemingly wakeful subjects, possibly in a state of subcortical wakefulness. In such cases, the subjects seem to be completely awake and respond to verbal orders but, after elapsing the effects of the drug, retain no memory of their acts (Wikler 1952; Ostfeld et al., 1960; Vanderwolf, 1988; Schallert et al., 1980; Dringenberg \& Vanderwolf, 1997; Castro-Zaballa et al., 2019). We should thus conclude that the presence of delta EEG cannot be used to automatically presume the presence of NREMS. What characterizes the state of an animal is the behavior and not an EEG pattern. 
The delta waves of high amplitude reflect the synchronous activity of large populations of thalamocortical neurons firing in bursts, interspersed with prolonged hyperpolarizations (Glenn and Steriade, 1982; Steriade, 1991, Steriade et al, 1991; 1993; Steriade and McCarley, 2013) that interfere with the transfer of sensory-motor communication between thalamus and cortex (Coenen, 1995; Liu et al., 2020; Salih et al., 2005, 2009; Massimini et al., 2005).

\subsection{The contradictory homeostatic signs of wake}

Both rhombencephalic and cortical wakefulness always are states in which the homeostatic physiological regulation is disturbed. For instance, a grazing lamb may keep active its entire homeostatic regulation, but, when harassed by a wolf pack, the homeostatic stability disappears. In consequence, wakefulness may be considered as anti-homeostatic. The homeostasis aims at maintaining a physiological steady state (Cannon, 1929) but disregards the changes that may hinder the immediate survival (Laborit, 1976). The contrast gave origin to the concepts of Rheosthasis (Mrosovsky 1990) and Allostasis (McEwen and Wingfield, 2003). In neurological terms, the dominant cortical EEG of mammalian wake - the beta and gamma EEG - heralds the abandon of homeostasis. Indeed, wakeful animals - including REMW and cortical wake - must make continuous efforts for searching food, finding reproductive partners and escaping predators, always disregarding the immediate homeostatic regulations. These facts can be summarized affirming that active wakefulness generates an allostatic load that must be compensated with subsequent periods of rest, whose epiphenomenon, the Delta EEG power, marks the freedom of subcortical regions for recovering the homeostatic steady state (Halász \& Bódizs, 2013; Knyazev, 2012).

Delta EEG may also be recorded in wakeful poikilothermic vertebrates (De Vera et al., 1994; González et al., 1999; Csernai et al., 2019; Piercy et al., 2015; Abe et al., 
2015; Halász \& Bódizs, 2013; Knyazev, 2012; Low et al., 2008; Bullock \& Basar, 1988) heralding the low activity of their reduced pallium which remains blocked when the basic homeostatic functions require the activity of brainstem areas leaving apart the pallial interferences. In fact, the mammalian delta EEG power is indicative of partial or total functional decortication (Patron et al., 2019; Walter et al., 2019). Therefore, the basic meaning of SWEEG waves is the same in mammals and in poikilothermic animals: blocking the anti-homeostatic cortical activity and freeing subcortical regions to perform essential housekeeping - homeostatic - activities (Rial et al, 2010).

The presence of rapid EEG - beta EEG - with low amplitude, mixed frequency waves - is the basic sign of the mammalian wake, but it also appears during REMS (Dement \& Kleitman, 1957; Maloney et al., 1997; Vyazovskiy et al., 2009). However, the beta EEG recorded in REM sleeping subjects is always accompanied by muscular atonia, which means that the REM beta EEG heralds a form of cortical wake devoid of motor output. The oneiric cortical activity lacks observable external consequences and, although might serve for important functions - largely unknown, for the time being might be, an epiphenomenon of the REMS cortical isolation. Indeed, it has been repeatedly recognized that lower brain regions are necessary and sufficient for generating REM sleep (Siegel et al., 2011; Weber et al., 2015; Luppi et al., 2012) and the REMS of primitive mammals, probably with low cortical development, is limited to rhombencephalon that may or may not be accompanied by beta EEG (Siegel et al, 1999). This fact prompted the affirmation that that the forebrain aspects of REMS, including the dreams and the fast EEG, are a relatively recent acquisition (Siegel, 1995; Siegel et al.,1998, 1999, 2004) and, since they lack salient phenotypic traits - other than the EEG - may have non adaptive significance. Indeed, the ability for animals to survive predatory attacks, for example, is based on whether they show well-adapted behavioral 
patterns, but it is not because they show a certain type of EEG or experiencing certain dreams. This assertion might seem disputable, but it is not: the burden of the proof must always be charged to the defenders of an adaptation (Williams 1966/2018) and the adaptive function(s) of dreams still are in the realm of unproven hypothesis. Otherwise, we would be forced to make careful experimental analysis for arguing, for example, against the significance of premonitory dreams (Rial et al., 2007c).

Summarizing, the EEG is not a reliable indicator of the behavioral state in animals other than adult marsupials and placental mammals. We mentioned the presence of SWEEG in wakeful reptiles, but SWEEG is also observed in awake newborn mammals (Emde, and Metcalf, 1968; Vecchierini et al., 2007; André et al., 2010) and in REM sleeping platypuses, that can switch between slow and fast EEG, a fact that is correlated, probably, to substantial differences in the primitive working mode of the cortex (Krubitzer et al.,1995). Wakeful placental adult mammals consistently show fast, small amplitude, mixed frequency EEG because of the excitatory activity of cholinergic and serotonergic neurons of the basal telencephalon and the rafe, respectively (Dringenberg \& Vanderwolf, 1997, 1998; Szymusiak et al., 2000). In the words of Steriade, \& McCarley, (2013) the beta and gamma EEG herald the fine sculpturing of activation-inhibition of different cortical areas necessary to perform the multisensory analysis of the environment, that is, to attain a full cortical wakefulness.

4.2. The phylogenetic development of NREMS and REMS: divergence or convergence?

An important EEG disparity was observed after comparing the polygraphic sleep in the platypus and in cats, as representative of primitive and modern mammals, respectively. Two types of REM were found in the platypus, with moderate but also with high voltage EEG. Then, the firing activity of pontine neurons was found to be 
similar in sleeping cats and echidnas (Siegel et al., 1996). As a result, the authors concluded that NREM and REM were the result of the divergent differentiation of a primitive sleep state with mixed NREM-REM characteristics. i.e., high voltage EEG, as typical of NREMS, together with the behavioral signs of the platypus REM (Siegel et al., 1996). The platypus seemed to be the intermediate step between the REMS of echidnas, with SWEEG, and modern mammals with low amplitude, mixed frequency EEG (Siegel et al., 1999).

Thereafter, the polygraphic sleep was studied in a primitive bird, the ostrich (Strutio camelis). The results seemed to add evidence to the mixed NREM-REM hypothesis, because the forebrain EEG of NREM sleeping ostriches oscillated between high frequency, low voltage EEG waves and SWEEG (Lesku et al., 2011). Therefore, mammals and birds seemed to have followed a parallel evolution. Both began showing a primitive sleep, with mixed NREM-REM traits that in modern mammals and birds diverged to end as the well-differentiated NREMS and REMS.

The preponderance of REMS in young mammals is well known. On the other hand, the length of the REMS episodes and the total amount of REM sleeping time of ostriches is longer than that of any other bird (Rattenborg et al., 2009). Therefore, an even greater proportion of REMS should be observed in ostrich chicks. Unexpectedly, a recent study reported substantially smaller amounts of REM in chicks than in adult ostriches, with no significant changes in NREMS. Therefore, the ontogenesis of REMS in ostriches seems to be remarkably different from that observed in mammals and birds (Lyamin et al., 2020). 


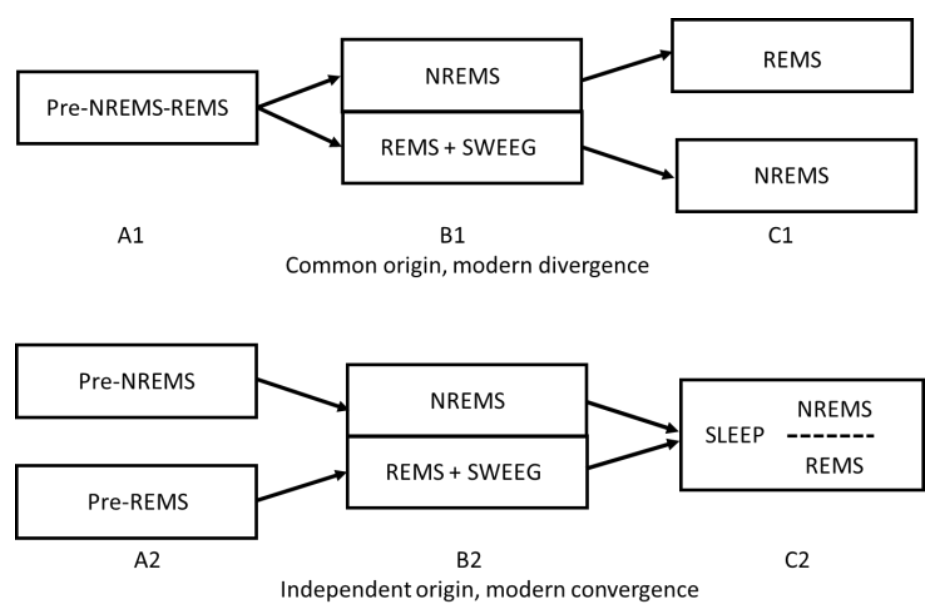

Figure 1. Two alternatives to explain the origin of NREM and REM.

The conundrum continues. The sleep of another primitive bird, the tinamou (Eudromia elegans), rendered the typical, well-differentiated EEG of NREMS and REMS of modern birds (Tisdale et al., 2017). Regretfully, the authors concluded that, although the tinamou data does not rule out the possibility that the ancestor of extant birds would exhibit a mixed ostrich-like/platypus-like sleep state, it does complicate the initial interpretation. Obviously, the complexity was furtherly increased after the data obtained from ostrich chicks

It should be noted, however, that the main empirical data used to affirm the existence of a primitive state with mixed NREM-REM traits was the presence of SWEEG both in platypus (Siegel et al., 1998) and in ostriches (Rattenborg et al., 2009). We may remember, however, the low value of the SWEEG for the differential diagnosis of sleep stages (see $\S 4$ ).

Furthermore, the presence of mixed NREM-REM traits cannot be used as a signpost to mark the direction of the evolutionary arrow (see figure 1) and the arrow can be directed towards divergence, i.e, instead of marking the transition from a mixture of pre-REMS-REMS to independent NREMS and REMS (A1 to C1, Figure 1), it can also be interpreted as signaling in the opposite direction, i.e., towards convergence from 
REMW and NREMW to mere sleep, a possibility also has been suggested by Corner and Schenk (2015).

It seems that the existence of NREMS and REMS has remained well hidden from human observers and, most likely, from the natural selection (Rial et al., 2007a). In fact, both names "NREM" and "REM" are always appended with the word "sleep". Therefore, both may be considered two forms of a single behavioral state: Sleep.

\section{Animals with anomalous REMS}

\subsection{The REMS of monotremes}

Up to now, five monotreme species have been recognized, the Platypus (Ornithorhynchus anatinus) and four echidnas (Tachyglossus acculeatus, Zaglossus attenboroughi, Z. bruijnii and Z. bartoni. Sleep has been studied only in the platypus (Siegel et al.,1999) and in short-beaked echidnas, T. Acculeatus (Allison et al.,1972; Siegel et al., 1996; Nicol et al., 2000). Surprisingly, platypuses showed the highest amounts of REMS ever recorded in mammals, while echidnas seemed to show no REMS at all (but see Nicol et al., 2000).

To understand the platypus/echidna contrast, we will analyze the main ecological and ontogenetic traits of the two species. Twin juveniles are the most frequent offspring in platypuses (11 singletons, 54 twins and 5 triplets, according to the study of Burrell, (1927), cited by Hawkins and Battaglia, (2009). Besides, platypus females are pouchless. The sticky eggs are incubated between the female's tail and belly until hatching, which occurs about ten days after oviposition. Then, the mother keeps the hatching in a thermally isolated burrow (Bethge et al. 2004; Holland and Jackson 2002). In the first weeks, the mother also remains in the burrow, with only short absences (Holland and Jackson 2002). Therefore, the litter's BT and that of the mother must be approximately the same, i.e., high and stable. Thereafter, the mother 
progressively increases the time spent out of the burrow and, after 4-5 weeks, the visits become spaced every second day, suggesting the beginning of the pup's thermoregulation (Holland and Jackson 2002; Augee, et al., 2006). These sucklings gain clear advantages in showing twitches, jerks and calls to inform their state to the mother and to compete with siblings during the postnatal period, as described in $\S 2.3 .2$. Thereby, the twitching may have a highly significant adaptive value for immature platypuses, like for newborn rats.

Contrastingly, the mating period is the only time in which the otherwise solitary echidnas meet one another. A few weeks after mating, the female echidna lays a single, soft, leathery egg that remains in a temporary pouch, which the mother makes by folding a section of her lower abdominal skin, providing thus an average of $31-32^{\circ} \mathrm{C}$ to the egg, the normal temperature of active echidnas (Schmidt-Nielsen et al.,1966; Beard and Grigg, 2000). After approximately 10 days, a blind, hairless baby echidna (known as a "puggle") hatches from the egg and attaches itself to a milk patch placed inside the pouch (Rismiller \& Grutzner, 2019). While the puggle remains in the pouch with unlimited access to milk and free from competing siblings, it will never be hungry or cool, and the infant-mother communication for demanding milk and heat, as explained in $\S 2.3 .2$, would be unnecessary. Nevertheless, we will see that the absence of phasic signs of REMS cannot be interpreted as indicative of complete absence.

The puggle is carried in the pouch between 45 and 55 days before being placed alone in a specially dug nursery in which the young remain cool to the touch $\left(15-18{ }^{\circ} \mathrm{C}\right)$ and torpid between feeding sessions (Rismiller, 2018). This means that it is tolerant to hypothermia, or, in other words, it is in a poikilothermic state, probably REMS. Young echidnas have a prodigious ability to imbibe large amounts milk in a very short time (Griffiths 1965; Green et al. 1985). This allows the mother to leave the nursery and 
return to nurse the puggle for about 2 hours every 5 days (Griffiths, 1989; Beard and Grigg, 2000; Rismiller 1999; Rismiller and McKelvey 2009). Furthermore, the temperature of the mother rises during the visits. As echidnas lack defense against hyperthermia (Augee, 1976; Schmidt-Nielsen et al.,1966), the high BT attained by mothers during the feeding visits contrasts with the normal heterothermic pattern (Brice et al., 2002) and suggests that the increased heat production of the mother is used to rewarm the puggle before feeding (Griffiths et al.,1988; Beard and Grigg, 2000). This chain of behavioral activities can again be interpreted as indicative of high amounts of tonic, paralyzed, poikilothermic REMS when puggles are alone in the nursery. These, signs are interspersed with probable periods of REMW when the mother comes to warm the puggle (an example of tigmothermic behavior) and feed the puggle. The development of incipient homeothermy would mark the presence of typical NREMS and the abandon of the nursery, heralding thus the full cortical wakefulness.

Obviously, in the case of being cool and/or hungry, the solitary infant echidnas would obtain no advantage in showing the phasic signs of REMS - calls, jerks and twitches - and would save significant amounts of energy suppressing them when there is nobody around for giving help. However, we said that the absence of overt signs of phasic REM don't mean a total absence of REMS. Evidently, the undeveloped puggle can attach itself to the milk patch and not to other non-secreting regions of the pouch and actively suck milk (Griffiths 1965; Green et al. 1985). This state, therefore, fills the requirements to be considered a form of primitive wake, that, given the low brain development of the puggle, must be controlled from spinal-rhombencephalic regions. It is, therefore, REMW.

In summary, we maintain that the need for communication with the mother, together with the presence/absence of competition between siblings may be the factors 
determining the presence or absence of phasic signs of REMS in platypuses, in rat pups and in echidna puggles. Furthermore, we postulate that adult echidnas must have "hidden" REM. First, as an unavoidable consequence of their embryonary development- as in every other vertebrate - and second, because of the results obtained after comparing the activity of pontine neurons of echidnas and cats (Siegel et al., 1996). Indeed, the neurons of the echidna's brainstem reticular formation fire in the irregular burst-pause pattern typical of REMS and not in the slow, regular pattern of NREMS (Siegel and Tomaszewski, 1983; Huttenlocher, 1961). In addition, the main sign used for rejecting the presence of REMS in echidnas was the EEG (Allison et al., 1972, Siegel et al., 1996) and we already know the low significance of EEG for state definition in mammals other than Metatheria and Eutheria $(\S 4)$. Therefore, we propose that a significant part of the state showing high voltage EEG recorded in seemingly sleeping echidnas is in fact hidden REMS (or REMW), equivalent to the platypus REMH (REM sleep with high-voltage EEG) of Siegel et al., (1999).

\subsection{The absence of REMS in cetaceans}

No signs of sleep have been reported after parturition in cetaceans, neither in mothers nor in calves. This fact may be indicative of the dispensability of sleep, but here we will restrict the subject only to the absence of REMS in these animals (Mukhametov, 1988, 1995; Siegel, 2008; Lyamin et al., 2008) a fact that contradicts the well-known dominance of REMS in young mammals. The following paragraphs will try to explain this anomaly following the approach we used to explain the absence of overt signs of REMS in the echidna.

The BT of mammalian fetuses is slightly higher than that of the mother (Symonds \& Lomax 1992; Wood \& Beard, 1964; Schroder et al., 1987) and, in all newborn mammals, parturition involves a steep thermal shock. We have retrieved no 
report specifically dealing with the BT of newborn cetaceans, but it is known that parturition preferably occurs in epochs with the warmest water temperatures (Mann et al. 2000). First, this highlights the importance of the thermal requirements of newborn calves (Dunkin et al., 2005). Second, that cetacean mothers try to reduce the thermal stress of calves. Taking bottlenose dolphins as an example, the temperature step between uterus and free life in water, range from $\sim 35-36{ }^{\circ} \mathrm{C}$, (the rectal temperature of the mother) and $\sim 25^{\circ} \mathrm{C}$, (the water temperature in the Pacific Ocean during summer) (Terasawa et al., 1999). Given that newborn cetaceans lack the blubber isolation of adults (Rendell et al., 2019) and that the free life of calves begins submerged in water, the heat losses should be extremely high, and the energetic expenditures needed to maintain homeothermy would be hardly supportable. In fact, a naked human baby exposed at birth to an environmental temperature of $23{ }^{\circ} \mathrm{C}$ suffers the same rate of heat loss as a naked adult at $0{ }^{\circ} \mathrm{C}(\mathrm{WHO}, 1997)$ a shock that, given the thermal properties of water, must be much higher in dolphin calves. Considering also that the control of BT is rather unstable in most newborn mammals (da Mota Silveira et al, 2003; Mullany et al. 2010; Symonds \& Lomax, 1992; Mercer et al., 1979; Smales \& Kime, 1978), we can assume that newborn calves should begin their free life showing a rather low BT and should need a significant lapse of time to attain full homeothermy.

On the other hand, cetacean calves are always singletons (Rendell et al., 2019). Therefore, they will never be forced to compete with siblings. However, they do keep close contact with their mother for defense and lactation. Newborn cetacean cubs require huge amounts of lipid enriched milk for rapid growth of the subcutaneous blubber. Hence, mother and calf must keep constant visual and acoustic contact (Lyamin et al., 2005). Indeed, the calf normally swims in echelon under the mother's abdomen and tail, in order to obtain protection, easy nursing access and hydrodynamic 
pull (Noren et al., 2008; Noren \& Edwards 2011). Given that the full development of the cetacean brain lasts about 20 years (Ridgway et al., 2018) the existence of complete cortical wake in newborn cetacean calves seems highly improbable and the dominant state must be the rhombencephalic wake. Sound in water may reach the fetus, allowing an early development of auditory capabilities (Ridgway et al., 2018) and it has been found that in newborn dolphins, the auditory thresholds and sensitivity surpass those of adults, (Nachtigall et al, 2005; Sayigh et al., 1998; Wahlberg et al., 2017). Newborn calves also have high vocalization capabilities (McCowan \& Reiss, 1995; Smolker et al., 1993), a trait particularly important because they often wander away from their mothers, which poses safety risks. However, mothers usually retrieve their calves by actively signaling them to return using acoustic signals. Indeed, there are plenty of references explaining that each mother-calf pair produces distinctive whistles and clicks to maintain contact (Smolker et al., 1993; Mann \& Smuts, 1998; Killebrew et al., 2001; King et al., 2016a, b; Mello \& Amundin 2005; Morisaka et al., 2005; Kuczaj et al., 2015; Ames et al., 2019; Fripp et al., 2005).

We may remark here the striking similarity between the use of calls and jerks in rat pups, in platypuses and in cetacean calves. Furthermore, we already described the rhombencephalic vertebrate's capability for analyzing visual and acoustic cues and the probable existence in calves of enough rhombencephalic sensorimotor resources to follow the movements of their mother. Therefore, we see that the continuous wake of cetacean calves is equivalent, point by point, to the REMW of rat pups and echidna puggles. All appear in newborns, all are related to thermoregulatory and lactation needs, all involve visual and auditory cues that are dependent on hindbrain capabilities, and all show high survival value. The conclusion is that newborn cetaceans may lack overt REMS signs, but, most likely, they show REMW. 
The described coincidences offer a probable answer to the absence of REM in adult cetaceans. We should note that the mother-calf communication becomes unnecessary when the pups grow and become free from maternal care. In such cases the REM-associated signs of communication must vanish. Likewise, the REMS poikilothermy may be highly inconvenient for adults submerged in cool water. These facts explain why the phasic REMW signs can only be observed in immatures.

\subsection{The anomalous REM of pinnipeds}

Pinnipeds are precocial and, with rare exceptions (Spotte, 1982), are singletons (Riedman, 1990; Lyamin et al, 2018). In northern fur seals, the parturition occurs in summer on floating icebergs or on dry land, near the shore, within the Arctic Circle. In summer, the arctic weather is cloudy, with drizzle or heavy fog, strong winds, and a mean temperature of $7.5^{\circ} \mathrm{C}$ in July (Blix \& Steen, 1979). Thus, the polar regions impose various degrees of thermal stress, with high variability between different species (Dalton et al., 2014) but always depending on season, birthplace and, importantly, on maternal care (Blix \& Steen, 1979; Trillmich, 1990). Indeed, when the mother goes to forage, the pups may suffer hypothermia and newborn fur seals must endure a steep thermal shock. They possess efficient countercurrent heat saving mechanisms and show intense peripheral vasoconstriction, non-shivering (Lydersen \& Kovacs, 1999; Donohue et al., 2000; Pearson et al., 2014) and shivering thermogenesis (Davydov and Makarova, 1965; Hammel et al., 1977; Erdsack et al, 2013; Blix et al., 1979). However, in order to meet the high nutritional needs imposed by lactation, mothers often abandon their pups onshore and make long foraging trips of several hundreds of kilometers (Blix \& Steen, 1979; Georges et al., 2000). These absences often leave the pups near the limit of thermal tolerance where they may succumb in cool, rainy and windy days (Blix et al., 1979; Blix \& Steen, 1979). 
Altogether, this lifestyle seems quite similar to that of echidnas and should prevent the manifestation of REMS signs in pinnipeds. Paradoxically, they show normal signs of REMS when on land, while these signs disappear when sleeping in the sea (Lyamin et al.,1996; Madan and Jha, 2012). Furthermore, when returning to dry land they show no rebounds for recovering the lost REMS (Ungurean and Rattenborg, 2018: Lyamin et al., 2018).

Nevertheless, the presence of normal REMS onshore may be understood after considering that fur seals bred in large colonies (Boness et al, 1988; Kovacs et al., 1996) and mothers usually reject nursing alien pups. Therefore, they require an efficient system for mother-pup recognition. As in cetaceans, the system depends on acoustic communication, and the mother can recognize the voice of her pup between the multiple pups of the colony (Charrier et al. 2002; Kovaks, 1995). Consequently, the competition between the concert of calls and responses of the colony is equivalent to the competition between cetacean siblings and forces the production of distinctive mother-pup calls that, as in rats and cetaceans, may be dependent on rhombencephalic control and indicative of active REMW.

As in cetaceans, the overt signs of REMS are useful for the young pinnipeds but highly mal-adaptive in matures that can sleep afloat in the sea (Bourliere, 1967 cited by Zepelin et al, 1994). Indeed, the normal poikilothermy of REMS would involve huge heat loses in water life, but much less when ashore. These facts possibly explain the reduced and even the complete loss of REMS when fur seals sleep afloat in the sea (Lyamin et al., 2017) and its presence onshore.

\subsection{Anomalous REMS in land mammals}

\subsubsection{The REM Behavioral Disorder (RBD)}


The RBD is an evident and undisputed example of pathological REMW. It has been found in humans (Schenck et al., 1986; Corner and Schenk, 2015) and in experimental animals (Jouvet \& Delorme 1965). Apart from showing complete behavioral patterns (Blumberg \& Plumeau, 2016), the muscular activity of RBD is quite similar to that of vertebrate embryos (Shukla et al, 2019; Kotagal, 2015; Suzue et al., 1999; Saint-Amant and Drapeau, 1998), as well as in fetal and postnatal movement of pattern mammals (Corner and Schenk, 2015).

The syndrome of Parasomnia Overlap has been defined as a set of sleep parasomnias associated to motor dyscontrol that may appear either during NREMS or REMS (Freedom 2013). When occurring during NREMS are considered disorders of arousal (AASM, 2005) and include somnambulism, confusional arousals and night terrors, but when occur during REMS are considered RBD. Most likely, the syndrome of parasomnia overlap consists in a pathological combination of different types of wakefulness, including, not only REMW but also signs of NREM wake.

\subsubsection{The behavior of precocial animals}

Another example of REMW may be found in the behavior of precocial newborns. As expected, the development at birth of their brains is more advanced than that of altricial species, but it is still under the final adult's size (Minervini et al., 2016; Ernst et al, 2018). In pigs and wild boars, for instance, the brain mass increases about 4 times between birth and full adulthood, meaning that even in precocial species a substantial amount of brain growth still occurs after birth (Kruska 2005). Likewise, the weight of the cerebral hemispheres of precocial sheep at birth, is only a $52 \%$ of the adult size (McIntosh et al., 1979). Therefore, the presence of REMW is highly probable, not only in altricial, but also in precocial mammals 
The possibility of REMW is further enhanced after considering the simple behavioral patterns of newborn herbivores - keeping continuous olfactory, auditory and haptic contact with the mother, finding the nipple, sucking and running after the mother. Obviously, this set of activities may be easily included within the functional capabilities of the rhombencephalon, much like those described for immature echidnas, fur seals and cetacean calves. One would argue that olfaction, essential for consolidating the relation mother-newborn in precocial mammals (Mazzatenta et al., 2019; Houpt, 2002) should be dependent of the entire brain - including cortical regions. However, extra-bulbar olfactory receptors innervated from the terminal nerve (the cephalic pair 0) show multiple connections, not only to telencephalic regions but to the entire nervous system, including pontine motor areas of agnates (Von Bartheld, 2004; Kermen et al., 2013; Ryczko et al, 2013, 2016; Derjean et al., 2010; Pérez-Fernández et al, 2014), fish (Hara, 1994; Laberge \& Hara, 2001; Kasumyan, 2004) and amphibians (Mousley et al. 2006). These data show that rhombencephalic regions may show enough development to allow the olfactory guided behavior of newborn precocial mammals, in another example of REMW.

\subsubsection{The drowsiness of herbivores}

REMW may also be observed in adult mammals. This may be the case of the "standing sleep" of horses and cows. It is a state that shows an EEG with mixed wakesleep features and has been ill-defined as "drowsiness" (Ruckebusch, 1970, 1972; Dallaire and Ruckebusch, 1974; Hale \& Huggins, 1980; Willams et al., 2008) but, up to now, remains without satisfactory explanation. Indeed, these animals may stand up with minimal muscular effort because of the neuroanatomical features of their leg joints (Hildebrand, 1987; Peng \& Ding, 2014). Therefore, rumination is the single behavioral 
activity these animals must perform during their drowsiness. Once again, the amount of brain needed for these activities is quite small and suggests REMW.

\section{Redefining REMS}

Altogether, the proposed homologies between the states of immature vertebrates and the mammalian sleep stages may allow a functional and precise definition of REMS:

1) REMS is a paralyzed form of primitive rhombencephalic wake that only appears in sleeping mammals after the suspension of higher types of wake.

2) In cetaceans, the phasic signs of REMS are hidden. They appear in newborns in the form of REMW. In adults, the signs of REMW disappear, minimizing the heat loss determined by aquatic life. However, irrespective of being visible or not, the phasic signs of REM sleep must exist in cetacean embryos and newborns.

3) In newborn pinnipeds, the phasic signs of REMS are preserved, as well as in adults when sleeping in dry land. However, they disappear when sleeping in the sea. As cetaceans, pinnipeds suppress the phasic signs of REMS and, most important, the poikilothermy, to avoid the water-associated heat loss of the poikilothermic REMS.

4) Overt signs of REMS are observed only in species giving birth to multiple pups or in singletons that must compete with other young of the colony.

5) Overt REMS is never observed in species in which the mother, besides giving birth to a single pup, abandons the nest during extended periods of time, leaving the pup alone.

6) Overt signs of rhombencephalic wake (REMW) may be currently found in precocial species.

7. Physiological aspects of mammalian sleep and reptilian activity states 
Table I describes the peripheral vasodilation responsible for the descents in core/brain temperature, with the known increase in NREMS propensity (Dewasmes et al, 1996; Van Someren, 2004), whereas the peripheral vasoconstriction promotes the typical REMS rise in core/brain temperature (Charles et al. 1980; Murphy \& Campbell, 1997; Campbell \& Broughton, 1994; Kräuchi \& Wirz-Justice, 2001; Van Den Heuvel et al., 1998).

One may wonder why these vasomotor changes occur and why the peripheralcentral oscillations in temperature are related to sleep (Parmeggiani, 2007). These questions may be answered after observing that identical changes appear in the reptilian BB and GDB cycles. During BB, skin vasodilation is necessary for rapid warming of the body core, while during GDB, the peripheral vasoconstriction is compulsory in order to minimize the heat loss and optimize the GDB time (Grigg \& Alchin, 1976; Dzialowski \& O’Connor 2001; Seebacher \& Franklin, 2004; Voigt, 1975; Seebacher, 2000).

Table I. Thermal relationships and vasomotor changes in mammalian and reptilian states

\begin{tabular}{|c|c|c|c|c|}
\hline & Mammal & Reptiles & Mammal & Reptiles \\
\hline State & NREMS & Basking & REMS & GDB \\
\hline $\begin{array}{l}\text { Core } \\
\text { temperature. }\end{array}$ & Low & Low & High & High \\
\hline $\begin{array}{l}\text { Skin } \\
\text { temperature. }\end{array}$ & High & High & Low & Low \\
\hline
\end{tabular}




\begin{tabular}{|l|l|l|l|l|}
\hline Peripheral & Vasodilation & Vasodilation & Vasoconstriction & Vasoconstriction \\
circulation & & & & \\
\hline Heat flow & Core $\rightarrow$ Skin & Skin $\rightarrow$ Core & Skin $\rightarrow$ Core & Core $\rightarrow$ Skin \\
\hline
\end{tabular}

These results show that the reptilian thermal regulation is the cause, up to now unexplained, of the phase opposition between the oscillations that persist in the peripheral and core temperature of NREMS and REMS (Sarabia et al., 2008; OrtizTudela et al., 2014; Bonmati-Carrion et al., 2013; Martinez-Nicolas et al., 2013). The single difference between the vasomotor parameters of BB-GDB and those of NREMSREMS lies in the opposite direction of heat flow. Obviously, heat always flows from warm to cold regions, being only dependent on the thermal gradient between environment and body core. This gradient depends, in homeothermic mammals, on an internal source of heat, the endothermic metabolism, while in reptiles depends on the heat coming from external sources (heliothermy or tigmothermy). Note that the vasoconstriction (the vascular resistance) of peripheral and central vascular beds is identical in both groups.

\subsection{The homeostatic regulation of REMS}

The existence of homeostatic regulation for REMS has been recognized by many authors (Benington \& Heller, 1994; Park \& Weber, 2020; McCarthy et al., 2016; Weber et al., 2018; Brunner et al., 1990, Dijk and Czeisler, 1995, Wurts and Edgar, 2000; Dement, 1960; Agnew et al., 1967; Morden et al., 1967; Beersma et al., 1990). Among others, these authors observed that, when the expression of REMS is blocked, the REMS propensity increases, as shown by the repeated attempts to re-enter in REMS and 
the progressive increase in the number of phasic REM events (Vogel, 1975; Shea et al., 2008).

We want to mention the dissonance between the most salient signs of REMS and the concept of homeostatic regulation (Cannon, 1929). Indeed, the atonia, thermal poikilostasis and cardiorespiratory irregularities are a set of factors that could be rightly considered as anti-homeostatic. In an extreme antithetic contrast, the word “poikilostasis", coined by Parmeggiani (2011), represents the demolition of the physiological homeostasis. The epitome of poikilostasis is, precisely, the high sympathetic activity of REMS (Somers et al., 1993) responsible for the physiological lability in thermoregulatory (Parmeggiani, 1970, 1977, 2011) cardio-circulatory (Mancia \& Zanchetti, 1980) and respiratory (Phillipson, 1978; Sullivan 1980) activities. Under this viewpoint, the existence of homeostasis in REMS involves a new paradox (Parmeggiani, 2011) superposed to old paradoxical nature of REMS, (the EEG signature of waking, together with the behavioral signs of deep sleep, so well described by Aserinsky \& Kleitman, (1953) and Jouvet (1959). We are now referring to the "ultraparadoxical" aspect of REMS that may be responsible of the current ignorance of the nature of the REMS homeostatically regulated variable. Indeed, conciliating the general homeostatic regulation with the thermal, respiratory and cardio circulatory poikilostasis seems impossible and the homeostatic regulation of REMS should not exist. This has been argued by many researchers that consider that REMS must have some positive advantage to compensate their maladaptive aspect. This is precisely what we propose here: the advantage lies in an up to now overlooked, but well-known trait of REMS. The eye movements, twitches and jerks recorded in the adult's REMS are currently considered additional small mysteries within the seemingly incomprehensible set of mysterious REMS-associated signs. We now understand that, while being inconsequent 
in adults, they constitute a communication link of vital importance for the newborns' survival. Moreover, it also explains the carefully regulated antagonism between the pontine glycinergic inhibition and the glutamatergic stimulation of spinal moto-neurons that allow the drain of huge amounts of motor activity but, up to now puzzled sleep scholars.

It is evident that the positive value of the phasic signs observed in the newborn REMS outweighs, in most mammalian species, the negative thermal, respiratory and cardio-circulatory irregularities of adult REMS. The situation changes in adult marine mammals, in which the thermal constraints of aquatic life - high thermal conductivity and high specific heat - largely outweigh the importance of the already unnecessary phasic signs of the adult's REMS. Likewise, the cool related reductions in total REMS time are obvious avoidance responses appearing after incipient hypothermia (Parmeggiani and Rabini, 1970; Sichieri and Schmidek, 1984; Szymusiak et al.,1980; Szymusiak and Satinoff, 1981; Whitten et al.,2009). Therefore, the expression of adult's REMS might constitute a set of residual signs that persist because they causes no harm in thermoneutral environments.

Accordingly, we propose that the homeostatic regulation of the mammalian REMS depends on two mechanisms: first, on an already known permissive flip flop (Lu et al, 2006; Fuller et al., 2007; Chen et al, 2018) controlling the NREMS-REMS transitions by switching the interchange of heat between core and peripheral temperature (see table I) explaining so the REMS-related increases and the NREMrelated decreases in cephalic temperature, respectively (Deboer et al., 1994; Harding, et al., 2019; Parmeggiani et al., 2002; Amici et al., 1994, 1998, and 2008). Second, the homeostatic regulation of REMS also depends on a proportional control regulating the production of the REMS phasic signs, whose number and intensity would increase in 
proportion to the exposure to cool, hunger or to any other risk compromising the life of newborns.

The need of two regulatory systems for REMS may be easily understood if we remember the homology we proposed between reptilian and mammalian states. When the hypothalamus of a basking reptile reaches the preferred temperature, it must quickly switch to GDB but, if such change would be experimentally obstructed, the animal would show indefatigable attempts to re-enter in GDB, a state, that we know, is necessary to perform vital activities. Thus, the reptilian response to the GDB blockade is identical to that observed in REMS deprived mammals. We also understand that, besides the on-off switch controlling the exit from the reptilian $\mathrm{BB}$, the maintenance of the reptilian GDB also depends on a proportional regulatory system controlling the magnitude of the vital foraging, territorial (agonistic) and reproductive activities. It is evident that this regulatory mechanism persists in mammalian infants as a second proportional homeostatic control regulating the intensity of REMS, i.e., the frequency of calls, twitches and jerks, that increase or decrease in proportion to the cooling, hunger or danger.

Of course, the reptilian diurnal activity and the nocturnal rest are tightly regulated by a circadian clock, also coinciding with the well-known circadian regulation of REMS (Lee et al., 2009; Wurths \& Elgar, 2000; Czeisler et al, 1980

To conclude, we have defined the existence of two homeostatic systems regulating the presence-absence of REMS and the intensity of the REMS signs. We also explained the existence of circadian regulation for REMS. Both homeostatic and circadian factors involved in the regulation of REMS were inherited from similar regulatory systems present in the reptilian ancestors of mammals. Furthermore, the surprising way that mammals use to interchange heat between core and periphery during 
sleep constitute another proof for the homology between reptilian GDB and REM as well as between BB and NREM

8. The second part of the Crick and Mitchison dilemma

At this point, it is obvious that the results described in this report refer, almost exclusively, to developmental processes. Therefore, our search for answers to the first part of the Crick and Mitchison observations may have been accomplished. Now, we should find a response to the second part: "any purely developmental theory must account for the quite appreciable amount of sleep along adult life".

9. The adults' REMS is a neutral trait.

It is well-known that people taking SSRI antidepressants show important reductions in REMS without compensatory rebounds (McCarthy et al, 2016), without cognitive impairments (Flood \& Cherkin, 1987; Marwari \& Dawe, 2018; Gazea et al, 2019) and perhaps with discrete improvements in memory (Rasch et al., 2009). Furthermore, a single dose of fluoxetine administered to healthy humans provoked acute suppression of REMS in the first night, with no significant rebounds in the following three nights (Feige et al., 2002). In the same vein, traumatic hindbrain lesions caused persistent suppression of REMS, show no observable derangements (Osorio \& Daroff 1980; Lavie et al, 1984; Magidov et al, 2018). Likewise, cetaceans entirely lack REMS and fur seals show no REMS when in the sea, without REMS rebounds after returning to land. In summary, it seems 1) that REMS may disappear without consequences and 2) that the regulation of REMS can be put on and off, also without observable consequences (Ungurean \& Rattenborg, 2018).

In summary, if we consider the absence of observable impairment after REMS deprivation, we may propose that REMS persists because, in most adult mammalian 
species, REMS provides neither advantages, nor disadvantages. In other words, the presence of REMS in adults is a neutral trait devoid of adaptive significance.

This affirmation may seem preposterous and even anathema for most sleep scholars. It seems impossible that such an immensely complex state that is found in the vast majority of mammalian species may lack adaptive value.

\subsection{Neoteny}

Some unexplained traits observed in adults may simply be remnants of infantile traits that persist in adults despite the loss or change in adaptive significance. Such processes receive the generic name of Neoteny. A simple, but illustrative example is the bellybutton, a scar that remains from a structure of vital importance in the embryo, the connection with the placenta. However, the belly button remains in adults devoid of known utility. Likewise, most traits of REMS may have had highly adaptive value for infants but persist in adulthood with no known advantage, i.e. being neutral in some cases, and even highly mal-adaptive in others. This may be the case of the REMS poikilothermy of marine mammals. Please remember, however, that the loss of some the phasic signs of REMS is partial. Most signs still remain in the form of REMW. Therefore, the overt signs of REMS may be neutral, but the neutrality does not hold for the signs of REMW.

Simple epistemological rules may provide additional food for thought. First, it is well established that "adaptation is an onerous concept that should be invoked when necessary to explain the facts" (Williams, 1966/2018). It is in fact too easy to find ad hoc explanations for everything. It is even easy to imagine adaptive unfalsable explanations both for the presence and absence of a given trait. In such cases, if one 
adaptive explanation fails it is simply replaced by another, but sufficient ingenuity enables any trait to receive an adaptive explanation.

A corollary of the Williams statement is that the burden of the proof must be charged to the defenders of any eventual adaptation. All sleep researchers are aware of the inexistence of solid proof for the dozens of hypotheses developed to explain the adaptiveness of REMS. Therefore, these hypotheses should be - for the time being rejected. Either an undisputable, solid proof is provided, or the null hypothesis must prevail.

Still in epistemological terms, science should adopt a methodology based on falsifiability, because no number of experiments can ever prove a theory. On the contrary, a single experiment is enough for contradicting it (Popper, 1934/1959). In relation to REMS, the existence of a single adult individual surviving without REMS with no discernible health or cognitive dysfunction, or with no rebounds after long periods of REMS deprivation, is enough to reject all proposed hypotheses trying to explain the adaptive function of the adults REMS (Siegel, 2021).

Still in theoretical terms, two schools of evolutionary thinking have been defined: adaptationism (also called Panglossianism) and neutralism (Gould and Vrba, 1982). Panglosians believe that every stabilized anatomical or physiological trait visible in a living species must be adaptive. Otherwise, the proposed trait would never have appeared, or would never be maintained. Possibly, pure Panglossian scientists are inexistent. Conversely, neutralists believe in the dominance of neutral traits in populations. The best-known example of neutral mutations are the synonymous mutations in the ADN that, supposedly, cause neither advantage nor disadvantage for the survival of individuals (Kimura 1979). 
In fact, the Selection Coefficient of a given gen has been proposed as an index showing the strength of selection for, or against to, an animal homozygote for such gen (Bulmer, 1971; Herron and Freeman, 2014). In practical terms, the selection coefficient oscillates between +1 for those traits that would be extended to the entire population in a single generation and -1 for those that would cause death with zero descendants. In the middle, genes with indexes comprised between +1 and -1 would show increases or decreases in frequency, respectively, after a finite number of generations, while those with a zero index would represent an absolute neutrality. It is evident that, discarding spontaneous random mutations or genetic drift, those traits with selection coefficients approaching zero would need a high number of generations and an extreme environmental constancy to become established or discarded in the entire population. Regarding REMS, it is evident that the possession of genes to show phasic signs of REMS in newborns must have, with few exceptions, a high positive adaptive value, but negative for adult cetaceans, pinnipeds and newborn echidnas. The index would be zero, i.e., neutral, in animals that sleep in thermoneutral environments, i.e., in well isolated nests or burrows. This is the case of most adult mammals - including humans - that sleep in well isolated nests or burrows with no noticeable disturbances in core body temperature, despite supporting significant episodes of poikilothermic REMS.

In conclusion, the proposed function for the phasic signs of REMS in immature mammals, as well as the REMS anomalies observed in vertebrate embryos, primitive mammals, marine mammals, depressive humans, RBD patients, precocial animals, and animals showing drowsiness, are consistent with experimental evidence, with the epistemological roots of science and with the current knowledge of population genetics. Such consistency strongly supports the assumption that REMS serves as an efficient 
communication system between mammalian mothers and infants but, most likely, is a neutral trait in most adult terrestrial mammals.

As a final note, the present report only deals with the wake states of vertebrates and its relationships with the mammalian sleep. Obviously, our results cannot be applied neither to birds, nor to poikilothermic vertebrates or invertebrates. Therefore, we should conclude that the evolutionary pathway defined for the development of sleep in non-mammals may have no relation with that of mammals. Indeed, the sleep of nonmammalian animals must have appeared as result of evolutionary convergence.

\section{REFERENCES}

AASM (American Academy of Sleep Medicine) (2005) International classification of sleep disorder. Second edition. Diagnostic and coding manual.:139-47.

Abe, H., Kinoshita, K., Baba, K., Takano, S., \& Murakami, K. (2015). Analyzing brain waves for activity recognition of learners. In Information and Communication TechnologyEurAsia Conference (pp. 64-73). Springer, Cham.

Agnew Jr, H. W., Webb Jr, W. B., \& Williams Jr, R. L. (1967). Comparison of stage four and 1rem sleep deprivation. Perceptual and motor skills.

Alberts, J. R. (1978). Huddling by rat pups: Group behavioral mechanisms of temperature regulation and energy conservation. Journal of Comparative and Physiological Psychology, 92, 231-245.

Alberts, J. R. (2007). Huddling by rat pups: ontogeny of individual and group behavior. Developmental Psychobiology: The Journal of the International Society for Developmental Psychobiology, 49(1), 22-32.

Alheid, G. F., Milsom, W. K., \& McCrimmon, D. R. (2004). Pontine influences on breathing: an overview. Respiratory physiology \& neurobiology, 143(2-3), 105-114.

Allin, J. T., \& Banks, E. M. (1972). Functional aspects of ultrasound production by infant albino rats (Rattus norvegicus). Animal Behaviour, 20, 175-185.

Allison, T., Van Twyver, H., Goff, W.R. (1972) Electrophysiological studies of the echidna, Tachyglossus aculeatus I. Waking and sleep. Arch Ital Biol 110:145-184

Ames, A. E., Macgregor, R. P., Wielandt, S. J., Cameron, D. M., Kuczaj, S. A., \& Hill, H. M. (2019). Pre-and Post-Partum Whistle Production of a Bottlenose Dolphin (Tursiops truncatus) Social Group. International Journal of Comparative Psychology, 32. 
Amici, R., Cerri, M., Ocampo-Garcés, A., Baracchi, F., Dentico, D., Jones, C. A., ... \& Zamboni, G. (2008). Cold exposure and sleep in the rat: REM sleep homeostasis and body size. Sleep, 31(5), 708-715.

Amici, R., Zamboni, G., Perez, E., Jones, C. A., \& Parmeggiani, P. L. (1998). The influence of a heavy thermal load on REM sleep in the rat. Brain research, 781(1-2), 252-258.

Amici, R., Zamboni, G., Perez, E., Jones, C. A., Toni, I., Culin, F., \& Parmeggiani, P. L. (1994). Pattern of desynchronized sleep during deprivation and recovery induced in the rat by changes in ambient temperature. Journal of sleep research, 3(4), 250-256.

Amri, M., \& Car, A. (1988). Projections from the medullary swallowing center to the hypoglossal motor nucleus: a neuroanatomical and electrophysiological study in sheep. Brain research, 441(1-2), 119-126.

André, M., Lamblin, M. D., d'Allest, A. M., Curzi-Dascalova, L., Moussalli-Salefranque, F. T. S. N. T., Vecchierini-Blineau, M. F., ... \& Plouin, P. (2010). Electroencephalography in premature and full-term infants. Developmental features and glossary. Neurophysiologie clinique/Clinical neurophysiology, 40(2), 59-124.

Aserinsky, E., \& Kleitman, N. (1953). Regularly occurring periods of eye motility, and concomitant phenomena, during sleep. Science, 118(3062), 273-274.

Atkinson, J. 1984). Human visual development over the first 6 months of life. A review and a hypothesis. Human neurobiology, 32), 61-74.

Auclair, F., Valdés, N., \& Marchand, R. (1996). Rhombomere-specific origin of branchial and visceral motoneurons of the facial nerve in the rat embryo. Journal of Comparative Neurology, 369(3), 451-461.

Augee, M. L. (1976). Heat tolerance of monotremes. Journal of Thermal Biology, 1(3), 181-184.

Bass, A. H., \& Chagnaud, B. P. (2012). Shared developmental and evolutionary origins for neural basis of vocal-acoustic and pectoral-gestural signaling. Proceedings of the National Academy of Sciences, 109(Supplement 1), 10677-10684.

Basson, C. H., Levy, O., Angilletta Jr, M. J., Clusella-Trullas, S. (2017). Lizards paid a greater opportunity cost to thermoregulate in a less heterogeneous environment. Functional Ecology, 31(4), 856-865.

Bautista, A., Drummond, H., Martínez-Gómez, M., \& Hudson, R. (2003). Thermal benefit of sibling presence in the newborn rabbit. Developmental Psychobiology: The Journal of the International Society for Developmental Psychobiology, 43(3), 208-215.

Bautista, A., García-Torres, E., Martínez-Gómez, M., \& Hudson, R. (2008). Do newborn domestic rabbits Oryctolagus cuniculus compete for thermally advantageous positions in the litter huddle?. Behavioral Ecology and Sociobiology, 62(3), 331-339.

Beard, L., Grigg, G. C. (2000). Reproduction in the short-beaked echidna. In Proceedings of the Linnean Society of New South Wales, 122, 89-99). 
Beersma DG, Dijk DJ, Blok CG, Everhardus I (1990) REM sleep deprivation during 5 hours leads to an immediate REM sleep rebound and to suppression of non-REM sleep intensity. Electroencephalogr Clin Neurophysiol 76:114 -122.

Beitinger, T. L. \& Magnuson, J. J. (1979). Growth-rates and temperature selection of bluegill, Lepomis macrochirus. Transactions of the American Fisheries Society 108, 378- 382.

Benington JH, Heller HC (1994) REM-sleep timing is controlled homeostatically by accumulation of REM-sleep propensity in non-REM sleep. Am J Physiol 266: R1992R2000.

Bennett, A. F. (2010). Adaptation and the evolution of physiological characters. Comprehensive Physiology, 3-16. Comp Physiol, Suppl 30, pp 3-16.

Berk, M. L., \& Heath, J. E. (1976). Effects of preoptic, hypothalamic, and telencephalic lesions on thermoregulation in the lizard, Dipsosaurus dorsalis. Journal of Thermal Biology, $1(2), 65-78$.

Bernardi, G., Betta, M., Ricciardi, E., Pietrini, P., Tononi, G., \& Siclari, F. (2019). Regional delta waves in human rapid eye movement sleep. Journal of Neuroscience, 39(14), 2686-2697.

Berntson, G. G., \& Micco, D. J. (1976). Organization of brainstem behavioral systems. Brain research bulletin, 1(5), 471-483.

Berridge, C. W., Schmeichel, B. E., \& España, R. A. (2012). Noradrenergic modulation of wakefulness/arousal. Sleep medicine reviews, 16(2), 187-197.

Bethge, P., Munks, S., Otley, H., and Nicol, S. (2004). Platypus burrow temperatures at a subalpine Tasmanian lake. Proceedings of the Linnean Society of New South Wales $125,272-276$.

Bever, T. G. (1982). Regressions in mental development: Basic phenomena and theories. Hillsdale, NJ. Lawrence Erlbaum Associates, Inc.

Bicego, K. C., \& Branco, L. G. (2002). Discrete electrolytic lesion of the preoptic area prevents LPS-induced behavioral fever in toads. Journal of experimental biology, 205(22), 35133518.

Bicego, K. C., Barros, R. C., \& Branco, L. G. (2007). Physiology of temperature regulation: comparative aspects. Comparative Biochemistry and Physiology Part A: Molecular \& Integrative Physiology, 1473, 616-639.

Blix, A. S., \& Steen, J. B. (1979). Temperature regulation in newborn polar homeotherms. Physiological Reviews, 59(2), 285-304.

Blix, A. S., Miller, L. K., Keyes, M. C., Grav, H. J., \& Elsner, R.. (1979). Newborn northern fur seals (Callorhinus ursinus)--do they suffer from cold?. American Journal of PhysiologyRegulatory, Integrative and Comparative Physiology, 236(5), R322-R327. 
Blumberg M.S., Seelke, A.M. (2010) The form and function of infant sleep: from muscle to neocortex. In: Blumberg MS, Freeman JH, Robinson SR, editors. Oxford Handbook of Developmental Behavioral Neuroscience. Oxford University Press;. pp. 391-423.

Blumberg, M. S., \& Plumeau, A. M. (2016). A new view of "dream enactment" in REM sleep behavior disorder. Sleep medicine reviews, 30, 34-42.

Blumberg, M. S., Coleman, C. M., Gerth, A. I., \& McMurray, B. (2013). Spatiotemporal structure of REM sleep twitching reveals developmental origins of motor synergies. Current Biology, 23(21), 2100-2109.

Blumberg, M. S., Lucas D. E. (1994) "Dual mechanisms of twitching during sleep in neonatal rats." Behavioral neuroscience 108.6: 1196.

Blumberg, M. S., Stolba, M. A. (1996). Thermogenesis, myoclonic twitching, and ultrasonic vocalization in neonatal rats during moderate and extreme cold exposure. Behavioral neuroscience, 1102), 305.

Boness, D. J., Bowen, W. D., \& Oftedal, O. T. (1988). Evidence of polygyny from spatial patterns of hooded seals (Cystophora cristata). Canadian Journal of Zoology, 66(3), 703-706.

Bonmati-Carrion, M. A., Middleton, B., Revell, V., Skene, D. J., Rol, M. A., and Madrid, J. A. (2013). Circadian phase assessment by ambulatory monitoring in humans: correlation with dim light melatonin onset. Chronobiol. Int. 31, 37-51. doi: $10.3109 / 07420528.2013 .820740$

Borbély, A. A. (1982). A two process model of sleep regulation. Hum neurobiol, 1(3), 195-204.

Borbély, A. A., Daan, S., Wirz-Justice, A., \& Deboer, T. (2016). The two-process model of sleep regulation: a reappraisal. Journal of sleep research, 25(2), 131-143.

Bourliere F. (1967) The Natural History of Mammals, 3rd ed. NewYork, Alfred A Knopf, , p 68.

Bradshaw, S. D., \& Main, A. R. (1968). Behavioural attitudes and regulation of temperature in Amphibolurus lizards. Journal of Zoology, 154, 193-221.

Brattstrom, B. H. (1971). Social and thermoregulatory behavior of the bearded dragon, Amphibolurus barbatus. Copeia, 484-497.

Braun, C. M. (2000). Neuropsychologie du développement. Flammarion Médecine-Sciences. Chaper 3, pp 35-67 (in French)

Brice, P. H., Grigg, G. C., Beard, L. A., \& Donovan, J. A. (2002). Patterns of activity and inactivity in echidnas (Tachyglossus aculeatus) free-ranging in a hot dry climate: correlates with ambient temperature, time of day and season. Australian Journal of Zoology, 50(5), 461-475.

Brooks, P. L., \& Peever, J. (2016). A temporally controlled inhibitory drive coordinates twitch movements during REM sleep. Current Biology, 26(9), 1177-1182.

Brown, R. E., \& McKenna, J. T. (2015). Turning a negative into a positive: ascending GABAergic control of cortical activation and arousal. Frontiers in neurology, 6, 135. 
Brua RB, Nuechterlein GL, Buitron D. (1996) Vocal response of eared grebe embryos to egg cooling and egg turning. Auk; 13: 525-33

Bruce Durie, D. J. (1981). Sleep in animals. Psychopharmacology of Sleep. Raven Press, New York, 1-18

Brudzynski, S. M. (2013). Ethotransmission: communication of emotional states through ultrasonic vocalization in rats. Current opinion in neurobiology, 23(3), 310-317.

Brudzynski, S. M., \& Fletcher, N. H. (2010). Rat ultrasonic vocalization: short-range communication. In Handbook of Behavioral Neuroscience. 19, 69-76.

Brudzynski, S. M., Iku, A., \& Harness, A. (2011). Activity of cholinergic neurons in the laterodorsal tegmental nucleus during emission of $22 \mathrm{kHz}$ vocalization in rats. Behavioural Brain Research, 2251), 276-283.

Brunner, D. P., Dijk, D. J., Tobler, I., \& Borbély, A. A. (1990). Effect of partial sleep deprivation on sleep stages and EEG power spectra: evidence for non-REM and REM sleep homeostasis. Electroencephalography and clinical neurophysiology, 75(6), 492499.

Bullock, T. H. (1984). Comparative neuroethology of startle, rapid escape, and giant fibermediated responses. In Neural mechanisms of startle behavior (pp. 1-13). Springer, Boston, MA

Bullock, T.H., Basar, E. (1988). Comparison of ongoing compound field potentials in the brain of invertebrates and vertebrates. Brain Research Reviews 13, 57-75.

Bulmer, M. (1971). The effect of selection on genetic variability. The American Naturalist, 105(943), 201-211.

Burrell, H. J. (1927). The Platypus: Its discovery, zoological position, form and characteristics, habits, life history, etc. Angus \& Robertson.

Butler, A. B., \& Hodos, W. (2005). Comparative vertebrate neuroanatomy: evolution and adaptation. John Wiley \& Sons.

Butler, A. B., Reiner, A., \& Karten, H. J. (2011). Evolution of the amniote pallium and the origins of mammalian neocortex. Annals of the New York Academy of Sciences, 12251, 14-27.

Campbell, S. S., \& Broughton, R. J. (1994). Rapid decline in BT before sleep: fluffing the physiological pillow?. Chronobiology international, 11(2), 126-131.

Cangiano, L., \& Grillner, S. (2003). Fast and slow locomotor burst generation in the hemispinal cord of the lamprey. Journal of neurophysiology, 89(6), 2931-2942.

Cannon, W. B. (1929). Organization for physiological homeostasis. Physiological reviews, 9(3), $399-431$.

Casterlin, M. E., \& Reynolds, W. W. (1977). Behavioral fever in anuran amphibian larvae. Life Sciences, 20(4), 593-596. 
Castro-Zaballa, S., Cavelli, M., González, J., Monti, J., Falconi, A., \& Torterolo, P. (2019). EEG dissociation induced by muscarinic receptor antagonists: Coherent $40 \mathrm{~Hz}$ oscillations in a background of slow waves and spindles. Behavioural brain research, 359, 28-37.

Charles, A. C., Janet, C. Z., Joseph, M. R., Martin, C. M. E., \& Elliot, D. W. (1980). Timing of REM sleep is coupled to the circadian rhythm of BTin man. Sleep, 2(3), 329-346.

Charrier I, Mathevon N, Jouventin P (2002) How does a fur seal mother recognize the voice of her pup? An experimental study of Arctocephalus tropicalis. J Exp Biol 205:603-612

Chatonnet, F., Thoby-Brisson, M., Abadie, V., del Toro, E. D., Champagnat, J., \& Fortin, G. (2002). Early development of respiratory rhythm generation in mouse and chick. Respiratory physiology \& neurobiology, 131(1-2), 5-13.

Chen, K. S., Xu, M., Zhang, Z., Chang, W. C., Gaj, T., Schaffer, D. V., \& Dan, Y. (2018). A hypothalamic switch for REM and non-REM sleep. Neuron, 97(5), 1168-1176.

Christian, K. A., \& Weavers, B. W. (1996). Thermoregulation of monitor lizards in Australia: an evaluation of methods in thermal biology. Ecological monographs, 66(2), 139-157.

Christian, K. A., \& Weavers, B. W. (1996). Thermoregulation of monitor lizards in Australia: an evaluation of methods in thermal biology. Ecological monographs, 66(2), 139-157.

Cirelli, C., \& Tononi, G. (2015). Cortical development, electroencephalogram rhythms, and the sleep/wake cycle. Biological psychiatry, 77(12), 1071-1078.

Coenen, A.M.L., 1995. Neuronal activities underlying the electroencephalogram and evoked potentials in sleeping and waking: implications for information processing. Neuroscience and Biobehavioural Process 19, 447-463.

Cohen, A. H., \& Wallén, P. (1980). The neuronal correlate of locomotion in fish. Experimental brain research, 41(1), 11-18.

Cohen, B. (1974) The vestibulo-ocular reflex arc. In Vestibular System 1: Basic Mechanisms (pp. 477-540). Springer, Berlin, Heidelberg.

Corner MA. (1985) Ontogeny of brain sleep mechanisms. In: Brain Mechanisms of Sleep (McGinty DJ et al, eds. ). Raven Press,

Corner, M. A. (1964). Localization of capacities for functional development in the neural plate of Xenopus laevis. Journal of Comparative Neurology, 123(2), 243-255.

Corner, M. A. (1977). Sleep and the beginnings of behavior in the animal kingdom-Studies of ultradian motility cycles in early life. Progress in Neurobiology, 8, 279-295.

Corner, M. A., \& Schenck, C. H. (2015). Perchance to dream? Primordial motor activity patterns in vertebrates from fish to mammals: their prenatal origin, postnatal persistence during sleep, and pathological reemergence during REM sleep behavior disorder. Neuroscience bulletin, 31(6), 649-662.

Corner, M.A., Crain, S.M. (1965). Spontaneous contractions and bioelectric activity after differentiation in culture of presumptive neuromuscular tissues of the early frog embryo. Experientia 21, 422-424 
Coureaud G, Schaal B, Coudert P, Hudson R, Rideaud P, Orgeur P (2000) Mimicking natural nursing conditions promotes early pup survival in domestic rabbits. Ethology 106:207225

Crawshaw, L. I., Moffitt, B. P., Lemons, D. E., \& Downey, J. A. (1981). The Evolutionary Development of Vertebrate Thermoregulation: The vertebrates, from fish to humans, have evolved a wide variety of systems to deal with variations in the environmental temperature. American scientist, 69(5), 543-550.

Crick F, Mitchison G. (1983). The function of dream sleep. Nature; 304:111-4

Csernai, M., Borbély, S., Kocsis, K., Burka, D., Fekete, Z., Balogh, V., ... \& Barthó, P. (2019). Dynamics of sleep oscillations is coupled to brain temperature on multiple scales. The Journal of physiology, 597(15), 4069-4086.

Curry, T., Egeto, P., Wang, H., Podnos, A., Wasserman, D., \& Yeomans, J. (2013). Dopamine receptor D2 deficiency reduces mouse pup ultrasonic vocalizations and maternal responsiveness. Genes, Brain and Behavior, 12(4), 397-404.

Czeisler CA, Zimmerman JC, Ronda JM, Moore-Ede MC, Weitzman ED (1980) Timing of REM sleep is coupled to the circadian rhythm of body temperature in man Sleep., 2, pp. 329346

da Mota Silveira, S. M., de Mello, M. J. G., de Arruda Vidal, S., de Frias, P. G., \& Cattaneo, A. (2003). Hypothermia on admission: a risk factor for death in newborns referred to the Pernambuco Institute of Mother and Child Health. Journal of tropical pediatrics, 49(2), 115-120.

Dallaire, A., \& Ruckebusch, Y. (1974). Sleep and wakefulness in the housed pony under different dietary conditions. Canadian Journal of Comparative Medicine, 38(1), 65.

Dalton, A. J., Rosen, D. A., \& Trites, A. W. (2014). Broad thermal capacity facilitates the primarily pelagic existence of northern fur seals (Callorhinus ursinus). Marine Mammal Science, 30(3), 994-1013.

Dattilo, M., Antunes, H. K. M., Medeiros, A., Mônico-neto, M., Souza, H. D. S., Lee, K. S., ... \& de Mello, M. T. (2012). Paradoxical sleep deprivation induces muscle atrophy. Muscle $\&$ nerve, 45(3), 431-433.

Davydov, A. F., \& Makarova, A. R. (1965). Changes in heat regulation and circulation in newborn seals on transition to aquatic form of life. Federation proceedings. Translation supplement; selected translations from medical-related science, 24(4), 563-566.

De Vera, L., González, J., Rial, R. V. (1994). Reptilian waking EEG: slow waves, spindles and evoked potentials. Electroencephalography and clinical neurophysiology, 904, 298-303.

De Vries, J. I., Visser, G. H. A., \& Prechtl, H. F. (1985). The emergence of fetal behaviour. II. Quantitative aspects. Early human development, 12(2), 99-120

Deboer, T., Franken, P., \& Tobler, L. (1994). Sleep and cortical temperature in the Djungarian hamster under baseline conditions and after sleep deprivation. Journal of Comparative Physiology A, 174(2), 145-155. 
Dement WC (1960) The effect of dream deprivation. Science 131:1705-1707

Dement, W. C. (2017). History of sleep physiology and medicine. In Principles and practice of sleep medicine. 3-15. Saunders.

Dement, W., \& Kleitman, N. (1957). Cyclic variations in EEG during sleep and their relation to eye movements, body motility, and dreaming. Electroencephalography and clinical neurophysiology, 9(4), 673-690.

Derjean, D., Moussaddy, A., Atallah, E., St-Pierre, M., Auclair, F., Chang, S., et al. (2010). A novel neural substrate for the transformation of olfactory inputs into motor output. PLoS Biol. 8:e1000567. doi: 10.1371/journal.pbio.1000567

Dewasmes, G., Signoret, P., Nicolas, A., Ehrhart, J., \& Muzet, A. (1996). Advances of human core temperature minimum and maximal paradoxical sleep propensity by ambient thermal transients. Neuroscience letters, 215(1), 25-28.

Dijk, D. J., \& Czeisler, C. A. (1995). Contribution of the circadian pacemaker and the sleep homeostat to sleep propensity, sleep structure, electroencephalographic slow waves, and sleep spindle activity in humans. Journal of Neuroscience, 15(5), 3526-3538.

Dominici, N., Ivanenko, Y. P., Cappellini, G., d'Avella, A., Mondì, V., Cicchese, M., ... \& Poppele, R. E. (2011). Locomotor primitives in newborn babies and their development. Science, 334(6058), 997-999.

Donohue, M. J., Costa, D. P., Goebel, M. E., \& Baker, J. D. (2000). The ontogeny of metabolic rate and thermoregulatory capabilities of northern fur seal, Callorhinus ursinus, pups in air and water. Journal of Experimental Biology, 203(6), 1003-1016.

Dos Santos, A. V., Matias, S., Saraiva, P., \& Goulão, A. (2006). MR imaging features of brain stem hypoplasia in familial horizontal gaze palsy and scoliosis. American journal of neuroradiology, 27(6), 1382-1383

Dringenberg, H. C., \& Vanderwolf, C. H. (1997). Neocortical activation: modulation by multiple pathways acting on central cholinergic and serotonergic systems. Experimental brain research, 116(1), 160-174.

Dringenberg, H. C., \& Vanderwolf, C. H. 1998). Involvement of direct and indirect pathways in electrocorticographic activation. Neuroscience \& Biobehavioral Reviews, 222), 243257.

Drummond H, Vázquez E, Sánchez-Colón S, Martínez-Gómez M, Hudson R (2000)

Competition for milk in the domestic rabbit: survivors benefit from littermate deaths. Ethology 106:511-526

Dubowitz, L. M. S., De Vries, L., Mushin, J., \& Arden, G. B. (1986). Visual function in the newborn infant: is it cortically mediated?. The Lancet, 327(8490), 1139-1141.

Dunkin RC, McLellan WA, Blum JE, Pabst DA (2005) The ontogenetic changes in the thermal properties of Atlantic bottlenose dolphin blubber (Tursiops truncatus). J Exp Biol 208: $1469-1480$ 
Dzialowski, E. M., \& O’Connor, M. P. (2001). Physiological control of warming and cooling during simulated shuttling and basking in lizards. Physiological and Biochemical Zoology, 745), 679-693.

Emde, R.N.; Metcalf, D.R. (1968) Behavioral and EEG correlates of undifferentiated eye movement states in infancy. Psychophysiology 5: 227.

Erdsack, N., Dehnhardt, G., \& Hanke, W. (2013). Coping with heat: function of the natal coat of Cape fur seal (Arctocephalus pusillus pusillus) pups in maintaining core body temperature. PLoS One, 8(8), e72081.

Ernst, L., Darschnik, S., Roos, J., González-Gómez, M., Beemelmans, C., Beemelmans, C., ... \& Wahle, P. (2018). Fast prenatal development of the NPY neuron system in the neocortex of the European wild boar, Sus scrofa. Brain Structure and Function, 223(8), 3855-3873.

Evans RM. (1990) Vocal regulation of temperature by avian embryos: a laboratory study with pipped eggs of the american white pelican. Anim Behav; 40: 963-8.

Evans, R. M., A. Whitaker, and M. O. Wiebe. (1994). Development of vocal regulation of temperature by embryos in pipped eggs of ring-billed gills. Auk 111:596-604.

Feige, B., Voderholzer, U., Riemann, D., Dittmann, R., Hohagen, F., \& Berger, M. (2002). Fluoxetine and sleep EEG: effects of a single dose, subchronic treatment, and discontinuation in healthy subjects. Neuropsychopharmacology, 26(2), 246-258.

Ferrara, C. R., Vogt, R. C., \& Sousa-Lima, R. S. (2013). Turtle vocalizations as the first evidence of posthatching parental care in chelonians. Journal of Comparative Psychology, 1271, 24.

Field, J., Muir, D., Pilon, R., Sinclair, M., \& Dodwell, P. (1980). Infants' orientation to lateral sounds from birth to three months. Child Development, 295-298.

Firth, B. T., \& Turner, J. S. (1982). Sensory, neural and hormonal aspects of thermoregulation. Biology of the Reptilia, 12, 213-274.

Fitzgerald, M. (2005). The development of nociceptive circuits. Nature Reviews Neuroscience, $6(7), 507-520$.

Flanigan Jr, W. F., Wilcox, R. H., \& Rechtschaffen, A. (1973). The EEG and behavioral continuum of the crocodilian, Caiman sclerops. Electroencephalography and clinical neurophysiology, 34(5), 521-538.

Flood, J. F., \& Cherkin, A. (1987). Fluoxetine enhances memory processing in mice. Psychopharmacology, 93(1), 36-43.

Foa, A., Avery, R. A., \& Tosini, G. (1992). Body temperatures and exposure to sunshine of ruin lizards Podarcis sicula in central Italy. Amphibia-Reptilia, 13(2), 169-175.

Francis, P. L., Self, P. A., \& McCaffree, M. A. (1984). Behavioral assessment of a hydranencephalic neonate. Child development, 262-266. 
Frank, S. M., Raja, S. N., Bulcao, C. F., \& Goldstein, D. S. (1999). Relative contribution of core and cutaneous temperatures to thermal comfort and autonomic responses in humans. Journal of Applied physiology, 86(5), 1588-1593.

Freedom T. (2013) Parasomnia Overlap Disorder. In: Kothare S., Ivanenko A. (eds) Parasomnias. Springer, New York, NY.

Fripp DC, Owen E, Quintana-Rizzo E, Shapiro A, Buckstaff K, Jankowski K, Wells R, Tyack P (2005) Bottlenose dolphin (Tursiops truncatus) calves appear to model their signature whistles on the signature whistles of community members. Anim Cogn 8:17-26

Fuller, P. M., Saper, C. B., \& Lu, J. (2007). The pontine REM switch: past and present. The Journal of physiology, 584(3), 735-741.

Gamundí, A., Akaârir, M., Coenen, A. M., Esteban, S., Rial, R. V., \& Nicolau, M. C. 2005). Mammalian sleep may have no adaptive advantage over simple activity-rest cycles. Medical hypotheses, 641), 130-132.

García-García, F., \& Drucker-Colín, R. (1999). Endogenous and exogenous factors on sleepwake cycle regulation. Progress in neurobiology, 58(4), 297-314.

Garrick, L. D. (1979). Lizard thermoregulation: operant responses for heat at different thermal intensities. Copeia, 258-266.

Gazea, M., Del Rio-Bermudez, C., Nissen, C., \& Adamantidis, A. R. (2019). Functions and circuits of REM sleep. In Handbook of Behavioral Neuroscience (Vol. 30, pp. 249-267). Elsevier. Pharmacological Suppression of REM Sleep in Learning and Memory

Georges, J. Y., Bonadonna, F., \& Guinet, C. (2000). Foraging habitat and diving activity of lactating Subantarctic fur seals in relation to sea-surface temperatures at Amsterdam Island. Marine Ecology Progress Series, 196, 291-304.

Gerkema, M. P., Davies, W. I., Foster, R. G., Menaker, M., \& Hut, R. A. (2013). The nocturnal bottleneck and the evolution of activity patterns in mammals. Proceedings of the Royal Society B: Biological Sciences, 280(1765), 20130508.

Gilbert, A. N. (1995). Tenacious nipple attachment in rodents: the sibling competition hypothesis. Animal Behaviour, 50(4), 881-891.

Gilbert, C., McCafferty, D., Le Maho, Y., Martrette, J. M., Giroud, S., Blanc, S., \& Ancel, A. (2010). One for all and all for one: the energetic benefits of huddling in endotherms. Biological Reviews, 85(3), 545-569.

Glenn, L. L., \& Steriade, M. (1982). Discharge rate and excitability of cortically projecting intralaminar thalamic neurons during waking and sleep states. Journal of Neuroscience, 2(10), 1387-1404.

Golovanov, V. K. (2006). The ecological and evolutionary aspects of thermoregulation behavior on fish. Journal of Ichthyology, 46(2), S180-S187. 
González, J., Gamundi, A., Rial, R., Nicolau, M. C., de Vera, L., \& Pereda, E. (1999). Nonlinear, fractal, and spectral analysis of the EEG of lizard, Gallotia galloti. American Journal of Physiology-Regulatory, Integrative and Comparative Physiology, 277(1), R86-R93.

Gould, S.J. \& Vrba, E.S. (1982). Exaptation - a missing term in the science of form. Paleobiology8: 4-15

Gräns, A., \& Altimiras, J. (2007). Ontogeny of vocalizations and movements in response to cooling in chickens fetuses. Physiology \& behavior, 912-3), 229-239.

Green, B.F., Griffiths, M. and Newgrain, K.W. (1985). Intake of milk by suckling echidnas Tachyglossus aculeatus). Comparative Biochemistry and Physiology 81A: 441-444

Griffiths, M. (1989). Tachiglossidae. In Walton D.W. and Richardson, B.J. eds). Fauna of Australia. Mammalia. Pages 407-435

Griffiths, M., Kristo, F., Green, B., Fogerty, A.C. Newgrain K. (1988). Observations on free living lactating echidnas Tachiglossus acculeatus Monotremata: Tachiglossidae) and sucklings. Australian Mammalogy 11, 135-144

Griffiths, M.E. (1965). Rate of growth and intake of milk in a suckling echidna. Comparative Biochemistry and Physiology 16: 383-392

Grigg, G. C., \& Alchin, J. (1976). The role of the cardiovascular system in thermoregulation of Crocodylus johnstoni. Physiological Zoology, 49(1), 24-36.

Grillner, S., \& Wallen, P. (2002). Cellular bases of a vertebrate locomotor system-steering, intersegmental and segmental co-ordination and sensory control. Brain research reviews, 40(1-3), 92-106.

Grimwade, J. C., Walker, D. W., \& Wood, C. (1970). Sensory stimulation of the human fetus. Australian Journal of Mental Retardation, 1(2), 63-64.

Halász, P., \& Bódizs, R. (2013). Slow Wave Activity as Substrate of Homeostatic Regulation. In Dynamic Structure of NREM sleep (pp. 73-101). Springer, London.

Hale, L. A., \& Huggins, S. E. (1980). The electroencephalogram of the normal "grade" pony in sleep and wakefulness. Comparative Biochemistry and Physiology Part A: Physiology, 66(2), 251-257.

Halsey J.H., Jr., Allen, N., Chamberlin, HR. (1968). Chronic Decerebrate State in Infancy. Neurologic Observations in Long Surviving Cases of Hydranencephaly. Archives of Neurology 19:3 339-46;

Hammel, H. T., Elsner, R. W., Heller, H. C., Maggert, J. A., \& Bainton, C. R. (1977) Thermoregulatory responses to altering hypothalamic temperature in the harbor seal. American Journal of Physiology-Regulatory, Integrative and Comparative Physiology, 232(1), R18-R26.

Handa, Y., Naito, A., Watanabe, S., Komatsu, S., \& Shimizu, Y. (1986). Functional recovery of locomotive behavior in the adult spinal dog. The Tohoku journal of experimental medicine, 148(4), 373-384. 
Hara, T. J. (1994). Olfaction and gustation in fish: an overview. Acta Physiologica Scandinavica, 152(2), 207-217.

Harding, E. C., Franks, N. P., \& Wisden, W. (2019). The temperature dependence of sleep. Frontiers in neuroscience, 13, 336.

Hart, B. L. (1971). Facilitation by strychnine of reflex walking in spinal dogs. Physiology \& behavior, 6(5), 627-628.

Hawkins, M., Battaglia, A. (2009). Breeding behaviour of the platypus Ornithorhynchus anatinus) in captivity. Australian Journal of Zoology, 574), 283-293.

Heesy, C. P., \& Hall, M. I. (2010). The nocturnal bottleneck and the evolution of mammalian vision. Brain, behavior and evolution, 75(3), 195-203.

Helmbrecht, T. O., Dal Maschio, M., Donovan, J. C., Koutsouli, S., \& Baier, H. (2018). Topography of a visuomotor transformation. Neuron, 100(6), 1429-1445.

Herron, J.C. \& Freeman S., (2014) Evolutionary analysis, 5th ed. Pearson, pp 204.

Herzog, H. A., \& Burghardt, G. M. (1977). Vocalization in juvenile crocodilians. Zeitschrift für Tierpsychologie, 44, 294-304

Hildebrand, M. (1987). The mechanics of horse legs. American Scientist, 75(6), 594-601.

Hobson, J. A. (2009). REM sleep and dreaming: towards a theory of protoconsciousness. Nature Reviews Neuroscience, 10(11), 803-813.

Hofer, M. A. (2002). Unexplained infant crying: an evolutionary perspective. Acta Paediatrica, 91(5), 491-496.

Hoffman. J., Liss, L (1969). 'Hydranencephaly.' A Case Report with Autopsy Findings in a 7Year-Old Girl. Acta Paediatrica Scandinavia 58:3, 297-300;

Hoffmann, A., \& de Souza, M. B. C. (1982). Cardiovascular reflexes in conscious toads. Journal of the autonomic nervous system, 5(3), 345-355.

Holland, N., and S. M. Jackson. (2002). Reproductive behaviour and food consumption associated with the captive breeding of platypus Ornithorhynchus anatinus). J. Zool. 256:279-288.

Houpt, K. A. (2002). Formation and dissolution of the mare-foal bond. Applied Animal Behaviour Science, 78(2-4), 319-328.

Huang, H. T., Hwang, C. W., Lai, P. H., \& Chen, C. C. (2009). Möbius syndrome as a syndrome of rhombencephalic maldevelopment: a case report. Pediatrics \& Neonatology, 50(1), 36-38.

Huey, R. B. (1982). Temperature, physiology, and the ecology of reptiles. In Biology of the Reptilia, 12, 213-274.

Huey, R. B., \& Slatkin, M. (1976). Cost and benefits of lizard thermoregulation. The Quarterly Review of Biology, 51(3), 
Humphrey, T. (1964). Some correlations between the appearance of human fetal reflexes and the development of the nervous system. In Progress in Brain Research (Vol. 4, pp. 93-135). Elsevier.

Humphries, M., Gurney, K., \& Prescott, T. (2005). Action selection in a macroscopic model of the brainstem reticular formation. Modelling natural action selection, 61-68.

Huttenlocher, P. R. (1961) Evoked and spontaneous activity in single units of medial brain stem during natural sleep and waking. J. Neurophysiol. 24:451- 468.

Jane, J. A., Levey, N., \& Carlson, N. J. (1972). Tectal and cortical function in vision. Experimental neurology, 35(1), 61-77.

Jha,S.K.; Jones, B.E.; Coleman, T.; Steinmetz, N.; Law, C.; Griffin, G.; Hawk, J.; Dabbish, N.; Kalatsky, A.; Frank, M.J. (2005) Sleep-Dependent Plasticity Requires Cortical Activity. The Journal of Neuroscience 25: 9266-9274.

Johnson, M. H. (2001). Functional brain development in humans. Nature Reviews Neuroscience, 2(7), 475-483.

Joseph, R. (2000). Fetal brain behavior and cognitive development. Developmental review, 20(1), 81-98.

Jouvet M, Delorme F. Locus coeruleus et sommeil paradoxal. (1965) C R Soc Biol;159:895-9.

Jouvet M, Michel F, Courjon J. (1959) Sur un stade d'activite electrique cerebrale rapide au cours du sommeil physiologique. C R Soc Biol;153:1024-1028.

Jürgen, Z. (1980). Distribution of REM sleep in entrained 24 hour and free-running sleep-wake cycles. Sleep, 2(4), 377-389.

Kadić, A. S., \& Predojević, M. (2012). Fetal neurophysiology according to gestational age. In Seminars in Fetal and Neonatal Medicine (Vol. 17, No. 5, pp. 256-260). WB Saunders.

Karasov, W. H., \& Anderson, R. A. (1984). Interhabitat differences in energy acquisition and expenditure in a lizard. Ecology, 65(1), 235-247.

Kasumyan, A. O. (2004). The olfactory system in fish: structure, function, and role in behavior. Journal of Ichthyology, 44(2), S180.

Kermen, F., Franco, L. M., Wyatt, C., \& Yaksi, E. (2013). Neural circuits mediating olfactorydriven behavior in fish. Frontiers in neural circuits, 7, 62.

Khazipov, R., Sirota, A., Leinekugel, X., Holmes, G. L., Ben-Ari, Y., \& Buzsáki, G. (2004). Early motor activity drives spindle bursts in the developing somatosensory cortex. Nature, 432(7018), 758-761.

Khodadadifar, T. 2015). Development of smooth pursuit and predictive eye movements in fullterm and preterm infants: an occlusion study Master's thesis, NTNU).

Killebrew, D., Mercado, E., Herman, L., \& Pack, A. (2001). Sound production of a neonate bottlenose dolphin. Aquatic Mammals, 27, 34-44. 
Kimura, M. (1977). Preponderance of synonymous changes as evidence for the neutral theory of molecular evolution. Nature, 267(5608), 275-276.

King, S. L., Guarino, E., Donegan, K., Hecksher, J., \& Jaakkola, K. (2016b). Further insights into postpartum signature whistle use in bottlenose dolphins (Tursiops truncatus). Marine Mammal Science, 32, 1458-1469.

King, S. L., Guarino, E., Keaton, L., Erb, L., \& Jaakkola, K. (2016a). Maternal signature whistle use aids mother-calf reunions in a bottlenose dolphin, Tursiops truncatus. Behavioural Processes, 126, 64-70.

Kisilevsky, B. S., Fearon, I., \& Muir, D. W. (1998). Fetuses differentiate vibroacoustic stimuli. Infant Behavior and Development, 21(1), 25-46.

Kluger, M. J., Tarr, R. S., \& Heath, J. E. 1973). Posterior hypothalamic lesions and disturbances in behavioral thermoregulation in the lizard Dipsosaurus dorsalis. Physiological Zoology, 461), 79-84.

Knyazev, G. G. (2012). EEG delta oscillations as a correlate of basic homeostatic and motivational processes. Neuroscience \& Biobehavioral Reviews, 36(1), 677-695.

Komagata, N., Latifi, B., Rusterholz, T., Bassetti, C. L., Adamantidis, A., \& Schmidt, M. H. (2019). Dynamic REM sleep modulation by ambient temperature and the critical role of the melanin-concentrating hormone system. Current biology, 29(12), 1976-1987.

Kotagal, S. (2015). Rapid eye movement sleep behavior disorder during childhood. Sleep medicine clinics, 10(2), 163-167.

Kovacs KM (1995). Mother-pup reunions in harp seals, Phoca groenlandica: cues for the relocation of pups. Can J Zool 73:843-849

Kovacs, K. M., Lydersen, C., Hammill, M., \& Lavigne, D. M. (1996). Reproductive effort of male hooded seals (Cystophora cristata): estimates from mass loss. Canadian Journal of Zoology, 74(8), 1521-1530.

Kräuchi, K., \& Wirz-Justice, A. (2001). Circadian clues to sleep onset mechanisms. Neuropsychopharmacology, 25(1), S92-S96.

Krubitzer, L., Manger, P., Pettigrew, J., \& Calford, M. (1995). Organization of somatosensory cortex in monotremes: in search of the prototypical plan. Journal of Comparative Neurology, 351(2), 261-306.

Kruska DC. (2005) On the evolutionary significance of encephalisation in some eutherian mammals: effects of adaptive radiation, domestication, and feralization. Brain Behav Evol. 65: 73-108. pmid:15627722

Kuczaj, S. A. II, Eskelinen, HC, Jones, BL, \& Borger-Turner, JL (2015). Gotta go, mom's calling: Dolphin (Tursiops truncatus) mothers use individually distinctive acoustic signals to call their calves. Animal Behavior and Cognition, 2(1), 88-95. 
Kusuma, A., \& Ten Donkelaar, H. J. (1980). Propriospinal fibers interconnecting the spinal enlargements in some quadrupedal reptiles. Journal of Comparative Neurology, 193(4), 871-891.

Laberge, F., \& Hara, T. J. (2001). Neurobiology of fish olfaction: a review. Brain research reviews, 36(1), 46-59.

Laborit, H. (1976). On the mechanism of activation of the hypothalamo-pituitary-adrenal reaction to changes in the environment (the 'alarm reaction'). Resuscitation, 5(1), 1930.

Lacalli, T. C. (2001). New perspectives on the evolution of protochordate sensory and locomotory systems, and the origin of brains and heads. Philosophical Transactions of the Royal Society of London. Series B: Biological Sciences, 356(1414), 1565-1572.

Lavie, P., Pratt, H., Scharf, B., Peled, R., \& Brown, J. (1984). Localized pontine 1esion: Nearly absence of REM sleep. Neurology, 34(1), 118-118.

Lecanuet, J. P., \& Schaal, B. (1996). Fetal sensory competencies. European Journal of Obstetrics \& Gynecology and Reproductive Biology, 68, 1-23.

Lee, M. L., Swanson, B. E., \& Horacio, O. (2009). Circadian timing of REM sleep is coupled to an oscillator within the dorsomedial suprachiasmatic nucleus. Current Biology, 19(10), 848-852.

Lesku, J. A., Meyer, L. C., Fuller, A., Maloney, S. K., Dell'Omo, G., Vyssotski, A. L., and Rattenborg, N. C. (2011). Ostriches sleep like platypuses. PLoS One, 68), e23203.

Libourel, P. A., \& Barrillot, B. (2020). Is there REM sleep in reptiles? A key question, but still unanswered. Current Opinion in Physiology.

Libourel, P.A., Barrillot, B., Arthaud, S., Massot, B., Morel, A.L., Beuf, O., Herrel, A. and Luppi, P.H. (2018). Partial homologies between sleep states in lizards, mammals, and birds suggest a complex evolution of sleep states in amniotes. PLoS biology, 1610), p.e2005982.

Lister, B. C., \& Aguayo, A. G. (1992). Seasonality, predation, and the behaviour of a tropical mainland anole. Journal of Animal Ecology, 717-733.

Liu C, Li R, Liu Z, Yin S, Wang Z. (2006). The role of prostaglandins and the hypothalamus in thermoregulation in the lizard, Phrynocephalus przewalskii Agamidae). J Comp Physiol B;176:321-328.

Liu, D., Li, W., Ma, C., Zheng, W., Yao, Y., Tso, C. F., ... \& Paik, S. B. (2020). A common hub for sleep and motor control in the substantia nigra. Science, 367(6476), 440-445.

Lonstein JS, Simmons DA, Stern JM. (1998) Functions of the caudal periaqueductal gray in lactating rats: kyphosis, lordosis, maternal aggression, and fearfulness. Behav Neurosc 112:1502-18

Lovick, T. A. (1973) The behavioural repertoire of precollicular decerebrate rats. J. Physiol. 226: 4-6. 
Low, P. S., Shank, S. S., Sejnowski, T. J., \& Margoliash, D. (2008). Mammalian-like features of sleep structure in zebra finches. Proceedings of the National Academy of Sciences, 105(26), 9081-9086.

Lu, J., Sherman, D., Devor, M., \& Saper, C. B. (2006). A putative flip-flop switch for control of REM sleep. Nature, 441(7093), 589-594.

Lu, W., Zhang, M., Neuman, R. S., \& Bieger, D. (1997). Fictive oesophageal peristalsis evoked by activation of muscarinic acetylcholine receptors in rat nucleus tractus solitarii. Neurogastroenterology \& Motility, 9(4), 247-256.

Luppi, P. H., Clement, O., Sapin, E., Peyron, C., Gervasoni, D., Léger, L., \& Fort, P. (2012). Brainstem mechanisms of paradoxical (REM) sleep generation. Pflügers ArchivEuropean Journal of Physiology, 463(1), 43-52.

Lyamin, O. I., Kibalnikov, A. S., \& Siegel, J. M. (2020). Sleep in ostrich chicks (Struthio camelus). Sleep.

Lyamin, O. I., Kosenko, P. O., Korneva, S. M., Vyssotski, A. L., Mukhametov, L. M., \& Siegel, J. M. (2018). Fur seals suppress REM sleep for very long periods without subsequent rebound. Current Biology, 28(12), 2000-2005.

Lyamin, O. I., Manger, P. R., Ridgway, S. H., Mukhametov, L. M., \& Siegel, J. M. (2008). Cetacean sleep: an unusual form of mammalian sleep. Neuroscience \& Biobehavioral Reviews, 32(8), 1451-1484.

Lyamin, O. I., Mukhametov, L. M., Siegel, J. M. (2017). Sleep in the northern fur seal. Current opinion in neurobiology, 44, 144-151.

Lyamin, O. I., Oleksenko, A. I., Polyakova, I. G., \& Mukhametov, L. M. (1996). Paradoxical sleep in northern fur seals in water and on land. J Sleep Res, 5Suppl 1), 130.

Lyamin, O., Pryaslova, J., Lance, V., \& Siegel, J. (2005). Continuous activity in cetaceans after birth. Nature, 435(7046), 1177-1177.

Lydersen, C., \& Kovacs, K. M. (1999). Behaviour and energetics of ice-breeding, North Atlantic phocid seals during the lactation period. Marine Ecology Progress Series, 187, 265-281.

Madan, V., and Jha, S.K. (2012). Sleep alterations in mammals: Did aquatic conditions inhibit rapid eye movement sleep? Neurosci. Bull. 28, 746-758.

Madden, J. R., Kunc, H. P., English, S., Manser, M. B., \& Clutton-Brock, T. H. (2009). Calling in the gap: competition or cooperation in littermates' begging behaviour?. Proceedings of the Royal Society B: Biological Sciences, 276(1660), 1255-1262.

Magidov, E., Hayat, H., Sharon, O., Andelman, F., Katzav, S., Lavie, P., ... \& Nir, Y. (2018). Near-total absence of REM sleep co-occurring with normal cognition: an update of the 1984 paper. Sleep medicine, 52, 134-137

Maloney, K. J., Cape, E. G., Gotman, J., \& Jones, B. E. (1997). High-frequency $\gamma$ electroencephalogram activity in association with sleep-wake states and spontaneous behaviors in the rat. Neuroscience, 76(2), 541-555. 
Mamello, I., \& Amundin. M. (2005). Whistle production pre- and post-partum in bottlenose dolphins (Tursiops truncatus) in human care. Aquatic Mammals, 31, 169-175

Mancia, G., and Zanchetti, A. (1980) Cardiovascular regulation during sleep, in: Physiology in sleep. Research topics in physiology, vol.3, pp. 1-55. Eds J. Orem and C.D. Barnes. Academic Press, New York.

Mann J, Connor RC, Barre LM, Heithaus MR (2000) Female reproductive success in bottlenose dolphins (Tursiops sp.): life history, habitat, provisioning, and group-size effects. Behav Ecol 11: 210-219

Mann, J., \& Smuts, B. B. (1998). Natal attraction: Kidnapping, allocare, and separations among wild bottlenose dolphin (Tursiops truncatus) mothers and infants. Animal Behaviour, $55,1097-1113$.

Martinez-Nicolas, A., Ortiz-Tudela, E., Rol, M. A., \& Madrid, J. A. (2013). Uncovering different masking factors on wrist skin temperature rhythm in free-living subjects. PloS one, 8(4), e61142.

Marwari, S., \& Dawe, G. S. (2018). (R)-fluoxetine enhances cognitive flexibility and hippocampal cell proliferation in mice. Journal of Psychopharmacology, 32(4), 441457.

Massimini, M., Ferrarelli, F., Huber, R., Esser, S.K., Singh, H., Tononi, G., (2005) Breakdown of cortical effective connectivity during sleep. Science 309, 2228-2232.

Matern, S. A., Cech, J. J. \& Hopkins, T. E. (2000). Diel movements of bat rays, Myliobatis californica, in Tomales Bay, California: evidence for behavioral thermoregulation? Environmental Biology of Fishes 58, 173- 182.

Mazzatenta, A., Veronesi, M. C., Vignola, G., Ponzio, P., Carluccio, A., \& De Amicis, I. (2019). Behavior of Martina Franca donkey breed jenny-and-foal dyad in the neonatal period. Journal of Veterinary Behavior, 33, 81-89.

McCarthy, A., Wafford, K., Shanks, E., Ligocki, M., Edgar, D. M., \& Dijk, D. J. (2016). REM sleep homeostasis in the absence of REM sleep: Effects of antidepressants. Neuropharmacology, 108, 415-425.

McCowan, B., \& Reiss, D. (1995). Whistle contour development in captive-born infant bottlenose dolphins (Tursiops truncatus): Role of learning. Journal of Comparative Psychology, 109(3), 242.

McEwen B.S., Wingfield J.C. (2003) The concept of allostasis in biology and biomedicine Horm. Behav., 43, pp. 2-15.

McIntosh, G. H., Baghurst, K. I., Potter, B. J., \& Hetzel, B. S. (1979). Foetal brain development in the sheep. Neuropathology and applied neurobiology, 5(2), 103-114.

Mercer, J.B., Andrews, J.F. \& Szekely,M. (1979).Thermoregulatory responses in new born lambs during the first thirty-six hours of life. Journal of Thermal Biology 4,239245 
Merker, G. P., \& Nagy, K. A. (1984). Energy utilization by free-ranging Sceloporus virgatus lizards. Ecology, 65(2), 575-581.

Minervini, S., Accogli, G., Pirone, A., Graïc, J. M., Cozzi, B., \& Desantis, S. (2016). Brain mass and encephalization quotients in the domestic industrial pig (Sus scrofa). Plos one, 11(6), e0157378.

Mirmiran, M., Maas, Y. G., \& Ariagno, R. L. (2003). Development of fetal and neonatal sleep and circadian rhythms. Sleep medicine reviews, 7(4), 321-334.

Morales FR, Sampogna S, Rampon C, Luppi PH \& Chase MH (2006). Brainstem glycinergic neurons and their activation during active (rapid eye movement) sleep in the cat. Neuroscience 142, 37-47.)

Morden B, Mitchell G, Dement W (1967) Selective REM sleep deprivation and compensation phenomena in the rat. Brain Res 5:339 -349.

Morgan, H. D., Fleming A. S. \& Stern J. M.. (1992). Somatosensory control of the onset and retention of maternal responsiveness in primiparous Sprague-Dawley rats. Physiol. Behav. 51: 549-555.

Morisaka, T., Shinohara, M., \& Taki, M. (2005). Underwater sounds produced by neonatal bottlenose dolphins (Tursiops truncatus): I. Acoustic characteristics. Aquatic Mammals, 31,248 .

Morrison, A.R. (2005) The power of behavioral analysis in understanding sleep mechanisms. In: Parmeggiani, P. L.; Velluti, R. A. Eds. ), The Physiological Nature of Sleep. Imperial College Press, London, UK, pp. 187-206.

Morton, J., \& Johnson, M. H. (1991). CONSPEC and CONLERN: a two-process theory of infant face recognition. Psychological review, 98(2), 164.

Mousley, A., Polese, G., Marks, N. J., \& Eisthen, H. L. (2006). Terminal nerve-derived neuropeptide y modulates physiological responses in the olfactory epithelium of hungry axolotls (Ambystoma mexicanum). Journal of Neuroscience, 26(29), 7707-7717.

Mrosovsky, M. (1990) Rheostasis: The Physiology of Change, Oxford University Press, New York

Muir, D., \& Hains, S. (2004). The U-shaped developmental function for auditory localization. Journal of cognition and development, 5(1), 123-130.

Mukhametov, L.M., (1988). The absence of paradoxical sleep in dolphins. In: Koella,W.P., Obal, F., Schulz, H., Visser, P. (Eds.), Sleep 1986. Gustav Fischer Verlag,New York, pp. 154-156.

Mukhametov, L.M., (1995). Paradoxical sleep peculiarities in aquatic mammals. SleepRes. 24A, 202.

Mukherjee, A., Kumara, H. N., \& Bhupathy, S. (2018). Sun-basking, a necessity not a leisure: Anthropogenic driven disturbance, changing the basking pattern of the vulnerable 
Indian rock python in Keoladeo National Park, India. Global Ecology and Conservation, 13, e00368.

Mullany, L. C., Katz, J., Khatry, S. K., LeClerq, S. C., Darmstadt, G. L., \& Tielsch, J. M. (2010). Risk of mortality associated with neonatal hypothermia in southern Nepal. Archives of pediatrics \& adolescent medicine, 164(7), 650-656.

Murphy, P. J., \& Campbell, S. S. (1997). Nighttime drop in body temperature: a physiological trigger for sleep onset?. Sleep, 20(7), 505-511.

Muzet, A., Ehrhart, J., Candas, V., Libert, J. P., \& Vogt, J. J. (1983). REM sleep and ambient temperature in man. International Journal of Neuroscience, 18(1-2), 117-125.

Nachtigall, P.E., Yuen, M.M.L., Mooney, T.A., and Taylor, K.A. (2005). Hearing measurements from a stranded infant Risso's dolphin, Grampus griseus. J. Exp. Biol.208: 4181-4188. doi:10.1242/jeb.01876. PMID:16244176.

Nelson, D. O., \& Prosser, C. L. (1979). Effect of preoptic lesions on behavioral thermoregulation of green sunfish, Lepomis cyanellus, and of goldfish, Carassius auratus. Journal of Comparative Physiology A, 129(3), 193-197.

Nelson, D. O., Heath, J. E., \& Prosser, C. L. (1984). Evolution of temperature regulatory mechanisms. American Zoologist, 24(3), 791-807.

Newell, J. C. \& Quinn, T. P. (2005). Behavioral thermoregulation by maturing adult sockeye salmon (Oncorhynchus nerka) in a stratified lake prior to spawning. Canadian Journal of Zoology 83, 1232- 1239 .

Nichelmann M, Tzschentke B. (1997) Ontogeny of thermoregulation during the prenatal period in birds. Ann NY Acad Sci; 813: 78-86.

Nicol, S. C., Andersen, N. A., Phillips, N. H., \& Berger, R. J. (2000). The echidna manifests typical characteristics of rapid eye movement sleep. Neuroscience letters, 283(1), 49-52.

Nicolau, M.C., Akaârir, M., Gamundí, A., González, J., Rial, R.V., (2000). Why we sleep: the evolutionary pathway to the mammalian sleep. Progress in Neurobiology 62, 379-406.

Noren, S. R. (2008). Infant carrying behaviour in dolphins: costly parental care in an aquatic environment. Functional Ecology, 22(2), 284-288.

Noren, S. R., \& Edwards, E. F. (2011). Infant position in mother-calf dolphin pairs: formation locomotion with hydrodynamic benefits. Marine Ecology Progress Series, 424, 229236.

Oberlander, T. F., Grunau, R. E., Fitzgerald, C. \& Whitfield, M. F. (2002) Does parenchymal brain injury affect biobehavioral pain responses in very low birth weight infants at 32 weeks' postconceptional age? Pediatrics 110, 570-576

Ortiz-Tudela, E., Martinez-Nicolas, A., Albares, J., Segarra, F., Campos, M., Estivill, E., et al. (2014). Ambulatory circadian monitoring (ACM) based on thermometry, motor activity and body position (TAP): a comparison with polysomnography. Physiol. Behav. 126, 30-38. doi: 10.1016/j.physbeh.2013.12.009 
Osorio, I., \& Daroff, R. B. (1980). Absence of REM and altered NREM sleep in patients with spinocerebellar degeneration and slow saccades. Annals of Neurology: Official Journal of the American Neurological Association and the Child Neurology Society, 7(3), 277280.

Ostfeld, A. M., Machne, X., \& Unna, K. R. (1960). The effects of atropine on the electroencephalogram and behavior in man. Journal of Pharmacology and Experimental Therapeutics, 128(3), 265-272.

Pant, S., Kaur, G., \& De, J. K. (2010). Hydranencephaly. Kathmandu University Medical Journal, 8(1), 83-86.

Park, S. H., \& Weber, F. (2020). Neural and Homeostatic Regulation of REM Sleep. Frontiers in Psychology, 11, 1662.

Parmeggiani, P. L. (2007). REM sleep related increase in brain temperature: a physiologic problem. Archives italiennes de biologie, 145(1), 13-21.

Parmeggiani, P. L. (2011). Systemic homeostasis and poikilostasis in sleep: is REM a physiological paradox?. World Scientific.

Parmeggiani, P. L., \& Rabini, C. (1970). Sleep and environmental temperature. Archives italiennes de Biologie, 108(2), 369.

Parmeggiani, P. L., Azzaroni, A., \& Calasso, M. (2002). Systemic hemodynamic changes raising brain temperature in REM sleep. Brain research, 940(1-2), 55-60.

Parmeggiani, P.L., (1977) Interaction between sleep and thermoregulation. Waking Sleeping 123-132.

Patron, E., Mennella, R., Benvenuti, S. M., \& Thayer, J. F. (2019). The frontal cortex is a heartbrake: Reduction in delta oscillations is associated with heart rate deceleration. NeuroImage, 188, 403-410.

Pearson, L. E., Liwanag, H. E., Hammill, M. O., \& Burns, J. M. (2014). Shifts in thermoregulatory strategy during ontogeny in harp seals (Pagophilus groenlandicus). Journal of Thermal Biology, 44, 93-102.

Pedersen, C. A. (1997). Oxytocin control of maternal behavior regulation by sex steroids and offspring stimulia. Annals of the New York Academy of Sciences, 8071), 126-145

Peng, S., \& Ding, X. (2014). Revealing the mechanism of high loading capacity of the horse in leg structure. Chinese science bulletin, 59(21), 2625-2637. dead-point supporting effect the adjustment is to find a posture for mitigating the leg muscles burden and reducing energy consumptions.

Pérez-Fernández, J., Stephenson-Jones, M., Suryanarayana, S. M., Robertson, B., \& Grillner, S. (2014). Evolutionarily conserved organization of the dopaminergic system in lamprey: SN c/VTA afferent and efferent connectivity and D 2 receptor expression. Journal of Comparative Neurology, 522(17), 3775-3794. 
Petersson, P., Waldenström, A., Fåhraeus, C., \& Schouenborg, J. (2003). Spontaneous muscle twitches during sleep guide spinal self-organization. Nature, 424(6944), 72-75.

Phillipson, E.A., Respiratory adaptations in sleep. A. Rev. Physiol. 40 (1978) 133-156.

Piercy, J., Rogers, K., Reichert, M., Andrade, D. V., Abe, A. S., Tattersall, G. J., \& Milsom, W. K. (2015). The relationship between body temperature, heart rate, breathing rate, and rate of oxygen consumption, in the tegu lizard (Tupinambis merianae) at various levels of activity. Journal of Comparative Physiology B, 185(8), 891-903.

Piéron, H. (1912). Le problème physiologique du sommeil. Masson.

Pietruszka, R. D. (1986). Search tactics of desert lizards: how polarized are they?. Animal Behaviour, 34(6), 1742-1758.

Popper, K. (1959) The logic of scientific discovery Routledge publishers (ISBN 0-415-27844-9). Traslation of the german "Logik der Forschung", 1934

Rasch, B., Pommer, J., Diekelmann, S., \& Born, J. (2009). Pharmacological REM sleep suppression paradoxically improves rather than impairs skill memory. Nature neuroscience, 12(4), 396-397.

Rattenborg NC, Martinez-González D, Lesku JA. (2009) Avian sleep homeostasis: convergent evolution of complex brains, cognition and sleep functions in mammals and birds. Neurosci Biobehav Rev, 33: 253-270

Rendell, L., Cantor, M., Gero, S., Whitehead, H., \& Mann, J. (2019). Causes and consequences of female centrality in cetacean societies. Philosophical Transactions of the Royal Society B, 374(1780), 20180066.

Reynolds, W. W. \& Casterlin, M. E. (1979). Behavioral thermoregulation and locomotor-activity of Perca flavescens. Canadian Hydrobiologia, 75(2), 189-191.Journal of Zoology 57, $2239-2242$.

Reynolds, W. W., Casterlin, M. E., \& Covert, J. B. (1976). Behavioural fever in teleost fishes. Nature, 259(5538), 41-42.

Rial R.V., Nicolau, M.C. Gamundi, A., Akaârir, M., Aparicio, S., Garau, C., Tejada, S., Roca, C., Gené, L, Moranta, D. \& Esteban S. (2007a) The trivial function of sleep. Sleep Med. Rev., 114): 311-325

Rial R.V., Nicolau, M.C. Gamundi, A., Akaârir, M., Aparicio, S., Garau, C., Tejada, S., Roca, C., Gené, L, Moranta, D. \& Esteban S. (2007c) Sleep and wakefulness, trivial and nontrivial: Which is which? Sleep Medicine Reviews, 11, 411-417

Rial RV, Nicolau MC, Gamundi A, Akaarir M, Garau C, Aparicio S, Tejada S, Moranta D, Gene L, Esteban S. (2007c) Comments on evolution of sleep and the palliopallial connectivity in mammals and birds. Brain Res Bull. 724-6):183-6.

Rial, R. V., Akaârir, M., Gamundí, A., Nicolau, C., Garau, C., Aparicio, S., ... \& Coenen, A. M. (2010). Evolution of wakefulness, sleep and hibernation: from reptiles to mammals. Neuroscience \& Biobehavioral Reviews, 348), 1144-1160. 
Rial, R., Nicolau, M. C., Lopez-Garcia, J. A., \& Almirall, H. (1993). On the evolution of waking and sleeping. Comparative biochemistry and physiology. Comparative physiology, 104(2), 189-193.

Rial, R.V.; Canellas, F.; Gamundi, A.; Akaârir, M.; Nicollau, M.C. (2019). How The Mammalian Sleep Was Born. Preprints, 2019110387

Richards, J. E. (2001). Cortical indexes of saccade planning in infants. Infancy, 22, 123-133.

Ridgway, S. H., Carlin, K. P., \& Van Alstyne, K. R. (2018). Delphinid brain development from neonate to adulthood with comparisons to other cetaceans and artiodactyls. Marine Mammal Science, 34(2), 420-439

Riedman, M. (1990). The Pinnipeds: Seals, sea lions, and walruses. University of California Press.

Rismiller, P. (2018) Monotreme Genesis: wildlife care challenges. In https://www.awrc.org.au/uploads/5/8/6/6/5866843/48_rismiller__monotreme_genesis_awrc_2018_final.pdf

Rismiller, P. D. (1999). The echidna: Australia's enigma. Hugh Lauter Levin Associates.

Rismiller, P. D., \& Grutzner, F. (2019). Tachyglossus aculeatus (Monotremata: Tachyglossidae). Mammalian Species, 51(980), 75-91.

Rismiller, P. D., \& McKelvey, M. W. (2009). Activity and behaviour of lactating echidnas Tachyglossus aculeatus multiaculeatus) from hatching of egg to weaning of young. Australian Journal of Zoology, 574), 265-273.

Rivera-Vélez, N., \& Lewis, A. R. (1994). Threshold temperatures and the thermal cycle of a heliothermic lizard. Journal of Herpetology, 28, 1-6.

Roffwarg, H. P., Muzio, J. N., \& Dement, W. C. (1966). Ontogenetic development of the human sleep-dream cycle. Science, 152(3722), 604-619. https://doi.org/10.1126/science.152.3722.604

Rose, B. (1981). Factors affecting activity in Sceloporus virgatus. Ecology, 623), 706-716.

Rowe, J. W., Clark, D. L., Martin, C. E., \& Valle, C. (2020). Diel and seasonal variations in the thermal biology of San Cristobal Lava Lizards (Microlophus bivittatus). Journal of Thermal Biology, 88, 102518.

Ruckebusch, Y. (1970) Etude polygraphique et comportementale des états de veille et de sommeil chez la vache (Bos taurus), Ann. Rech. Vétér., 1 41-62

Ruckebusch, Y. (1972) The relevance of drowsiness in the circadian cycle of farm animals, Anim. Behav., 20 637-643.

Rumpf, M., \& Tzschentke, B. (2010). Perinatal acoustic communication in birds: Why do birds vocalize in the egg?. The Open Ornithology Journal, 31).

Ryczko, D., Cone, J. J., Alpert, M. H., Goetz, L., Auclair, F., Dubé, C., ... \& Dubuc, R. (2016). A descending dopamine pathway conserved from basal vertebrates to mammals. Proceedings of the National Academy of Sciences, 113(17), E2440-E2449. 
Ryczko, D., Grätsch, S., Auclair, F., Dubé, C., Bergeron, S., Alpert, M. H., ... \& Dubuc, R. (2013). Forebrain dopamine neurons project down to a brainstem region controlling locomotion. Proceedings of the National Academy of Sciences, 110(34), E3235-E3242.

Saint-Amant L, Drapeau P. (1998) Time course of the development of motor behaviors in the zebrafish embryo. J Neurobiol 1998, 37: 622-632.

Salih, F., Kathami, R., Steinheimer, S., Hummel, O., Kühn, A., Grosse, P., (2005). Inhibitory and excitatory intracortical circuits across the human sleep-wake cycle using the pairedpulse transcranial magnetic stimulation. Journal of Physiology 565, 695-701.

Salih, F., Sharott, A., Khatami, R., Trottenberg, T., Schneider, G., Kupsch, A., ... \& Grosse, P. (2009). Functional connectivity between motor cortex and globus pallidus in human non-REM sleep. The Journal of physiology, 587(5), 1071-1086.

Sarabia, J. A., Rol, M. A., Mendiola, P., \& Madrid, J. A. (2008). Circadian rhythm of wrist temperature in normal-living subjects: A candidate of new index of the circadian system. Physiology \& behavior, 95(4), 570-580.

Sastre JP, Sakai K \& Jouvet M (1981). Are the gigantocellular tegmental field neurons responsible for paradoxical sleep? Brain Res 229, 147-161.

Sayigh, L. S., Tyack, P. L., Wells, R. S., Solow, A. R., Scott, M. D., and Irvine, A. B. (1998). Individual recognition in wild bottlenose dolphins: a field test using playback experiments. Anim. Behav. 57, 41-50.

Schallert, T., De Ryck, M., \& Teitelbaum, P. (1980). Atropine stereotypy as a behavioral trap: A movement subsystem and electroencephalographic analysis. journal of Comparative and Physiological Psychology, 94(1), 1.

Schenck CH, Bundlie SR, Ettinger MG, Mahowald MW (1986). Chronic behavioral disorders of human REM sleep: a new category of parasomnia. Sleep;9:293-308

Schmidt-Nielsen, K., Dawson, T. J., \& Crawford, E. C. (1966). Temperature regulation in the echidna (Tachyglossus aculeatus). Journal of Cellular Physiology, 67(1), 63-71.

Schradin, C., Krackow, S., Schubert, M., Keller, C., Schradin, B., \& Pillay, N. (2007). Regulation of activity in desert-living striped mice: The importance of basking. Ethology, 113(6), 606-614.

Schroder, H.J., Huneke, B., Klug, A., Stegner, H., Carstensen, M.\& Leichtweib, H.P. (1987). Fetal sheep temperatures in utero during cooling and application of triiodothyronine, norepinephrine, propranolol and suxamethonium. Pfluigers Archiv 410,376-384

Schwarting, R. K., \& Wöhr, M. (2018). Isolation-induced ultrasonic vocalizations in pups: A comparison between Long-Evans, Sprague-Dawley, and Wistar rats. Developmental Psychobiology, 60(5), 534-543.

Schwartz, J. R., \& Roth, T. (2008). Neurophysiology of sleep and wakefulness: basic science and clinical implications. Current neuropharmacology, 6(4), 367-378. 
Seebacher, F. (2000). Heat transfer in a microvascular network: the effect of heart rate on heating and cooling in reptiles (Pogona barbata and Varanus varius). Journal of Theoretical Biology, 203(2), 97-109.

Seebacher, F., \& Franklin, C. E. (2004). Cardiovascular mechanisms during thermoregulation in reptiles. In International Congress Series (Vol. 1275, pp. 242-249). Elsevier.

Sévoz-Couche, C., Comet, M. A., Hamon, M., \& Laguzzi, R. (2003). Role of Nucleus Tractus Solitarius 5-HT3 Receptors in the Defense Reaction-Induced Inhibition of the Aortic Baroreflex in Rats. Journal of neurophysiology, 90(4), 2521-2530.

Shea, J. L., Mochizuki, T., Sagvaag, V., Aspevik, T., Bjorkum, A. A., \& Datta, S. (2008). Rapid eye movement (REM) sleep homeostatic regulatory processes in the rat: Changes in the sleep-wake stages and electroencephalographic power spectra. Brain research, 1213, 48-56.

Shein-Idelson, M., Ondracek, J. M., Liaw, H. P., Reiter, S., Laurent, G. (2016). Slow waves, sharp waves, ripples, and REM in sleeping dragons. Science, 3526285), 590-595.

Sherrington, C. S. (1910) Flexion-reflex of the limb, crossed extension reflex, and reflex stepping and standing. J. PhysioL 40: 28-121,.

Shewmon, D. A. (1988). Anencephaly: selected medical aspects. The Hastings Center Report, 18(5), 11-19.

Shim, H. S., \& Jeong, W. S. (2011). Suggested and preferred amount of clothing in a winter indoor condition. Journal of the Korean Society of Clothing and Textiles, 35(12), 14181424.

Shukla, G., Kotagal, S., \& Schenck, C. H. (2019). RBD in Childhood and Adolescence. In Rapid-Eye-Movement Sleep Behavior Disorder (pp. 187-200). Springer, Cham

Sichieri, R., \& Schmidek, W. R. (1984). Influence of ambient temperature on the sleepwakefulness cycle in the golden hamster. Physiology \& behavior, 33(6), 871-877.

Sicuro, F. L., Iack-Ximenes, G. E., Wogel, H., \& Bilate, M. (2013). Vocal patterns of adult females and juveniles Caiman yacare Crocodilia: Alligatoridae) in Brazilian Pantanal wetland. Revista de biologia tropical, 613), 1401-1413.

Siegel J. M. Manger PR, Nienhuis R, Fahringer HM, Pettigrew JD. (1998) Monotremes and the evolution of rapid eye movement sleep. Phil Trans Roy Soc Lond (B) 353: 1147-1157

Siegel JM (2011) REM. In: Kryger MH, Roth T, Dement WC, eds. Principles and Practice of Sleep Medicine, 5th ed. Philadelphia: WB Saunders. pp 92-111.

Siegel, J. M. (1995). Phylogeny and the function of REM sleep. Behavioural brain research, 69(1-2), 29-34. J.M.

Siegel, J. M. (2004). Sleep phylogeny: clues to the evolution and function of sleep. Sleep: circuits and functions. CRC Press, Boca Ranton, FL, 163-176.

Siegel, J. M. (2008). Do all animals sleep?. Trends in neurosciences, 31(4), 208-213. 
Siegel, J. M. (2021). Memory Consolidation Is Similar in Waking and Sleep. Current Sleep Medicine Reports, 1-4.

Siegel, J. M., and K. S. Tomaszewski (1983) Behavioral organization of reticular formation: Studies in the unrestrained cat. I. Cells related to axial, limb, eye, and other movements. J. Neurophysiol. 50: 696-716

Siegel, J. M., Manger, P. R., Nienhuis, R., Fahringer, H. M., \& Pettigrew, J. D. (1996). The echidna Tachyglossus aculeatus combines REM and non-REM aspects in a single sleep state: implications for the evolution of sleep. Journal of Neuroscience, 16(10), 35003506.

Siegel, J. M., Manger, P. R., Nienhuis, R., Fahringer, H. M., Shalita, T., \& Pettigrew, J. D. (1999). Sleep in the platypus. Neuroscience, 91(1), 391-400.

Sigvardt, K. A. (1989). Spinal mechanisms in the control of lamprey swimming. American zoologist, 29(1), 19-35.

Silkstone, M., \& Brudzynski, S. M. (2019). The antagonistic relationship between aversive and appetitive emotional states in rats as studied by pharmacologically-induced ultrasonic vocalization from the nucleus accumbens and lateral septum. Pharmacology Biochemistry and Behavior, 181, 77-85.

Smales, O., \& Kime, R. (1978). Thermoregulation in babies immediately after birth. Archives of disease in childhood, 53(1), 58-61.

Smolker, R. A., Mann, J., \& Smuts, B. B. (1993). Use of signature whistles during separations and reunions by wild bottlenose dolphin mothers and infants. Behavioral Ecology and Sociobiology, 33(6), 393-402.

Sohmer, H., \& Freeman, S. (1995). Functional development of auditory sensitivity in the fetus and neonate. Journal of basic and clinical physiology and pharmacology, 6(2), 95-108.

Soja PJ, Morales FR, Baranyi A \& Chase MH (1987). Effect of inhibitory amino acid antagonists on IPSPs induced in lumbar motoneurons upon stimulation of the nucleus reticularis gigantocellularis during active sleep. Brain Res 423, 353-358.

Somers, V. K., Dyken, M. E., Mark, A. L., \& Abboud, F. M. (1993). Sympathetic-nerve activity during sleep in normal subjects. New England Journal of Medicine, 328(5), 303-307.

Soussignan, R. (2003). Corticalité ou a-corticalité fonctionnelle chez le nouveau-né humain?. Enfance, 55(4), 337-357.

Souza, E., Coelho, A., Santos-Jr, A. P., Kawashita-Ribeiro, R. A., \& Fraga, R. D. (2020). Thermoregulation mode, substrate temperature and camouflage efficiency affecting defensive behavior of lizards in Amazonia. Acta Amazonica, 50(4), 339-345.

Spotte, S. (1982). The incidence of twins in pinnipeds. Canadian Journal of Zoology, 60(9), 2226-2233.

Srivastava, V. K. (1992). Functional recovery following reptilean (Calotijs calotijs) spinal cord transection. Indian J Physiol Phannacol, 36(3), 193-196. 
Stanton-Jones, W. K., Parusnath, S., \& Alexander, G. J. (2018). The impact of posture and basking orientation on thermoregulation in the Sungazer (Smaug giganteus). Journal of thermal biology, 75, 45-53.

Stehouwer, D. J., \& Farel, P. B. (1981). Sensory interactions with a central motor program in anuran larvae. Brain research, 218(1-2), 131-140.

Stehouwer, D. J., and P. B. Fare1 (1980) Central and peripheral controls of swimming in anuran larvae. Brain Res. 195: 323-335.

Steriade, M. (1991). Alertness, quiet sleep, dreaming. In Normal and Altered States of Function (pp. 279-357). Springer, Boston, MA.

Steriade, M. M., \& McCarley, R. W. (2013). Brainstem control of wakefulness and sleep. Springer Science \& Business Media.

Steriade, M., Dossi, R. C., \& Nunez, A. (1991). Network modulation of a slow intrinsic oscillation of cat thalamocortical neurons implicated in sleep delta waves: cortically induced synchronization and brainstem cholinergic suppression. Journal of Neuroscience, 11(10), 3200-3217.

Steriade, M., McCormick, D. A., \& Sejnowski, T. J. (1993). Thalamocortical oscillations in the sleeping and aroused brain. Science, 262(5134), 679-685.

Stern J.M, Dix L, Bellomo C, Thramann C. (1992) Ventral trunk somatosensory determinants of nursing behavior in Norway rats 2 . Role of nipple and surrounding sensations. Psychobiology; 20:71-80

Stern J.M. (1997) Offspring-induced nurturance: animal-human parallels. Developmental Psychobiology 31:19-37

Stern, J. M., \& Johnson, S. K. (1990). Ventral somatosensory determinants of nursing behavior in Norway rats. I. Effects of variations in the quality and quantity of pup stimuli. Physiology \& behavior, 47(5), 993-1011.

Stern, J.M. (1991). Nursing posture is elicited rapidly in maternally naive, haloperidol-treated female and male rats in response to ventral trunk stimulation from active pups. Hormones and behavior, 254), 504-517.

Strauss, S., \& Stavy, R. (Eds.). (1982). U-shaped behavioral growth. New York: Academic

Sullivan, E.C., (1980) Breathing in sleep, in: Physiology in sleep. Research topics in physiology, vol. 3, pp. 213-272. Eds J. Orem and C.D. Barnes. Academic Press, New York

Suzue T, Shinoda Y. (1999) Highly reproducible spatiotemporal patterns of mammalian embryonic movements at the developmental stage of the earliest spontaneous motility. Eur J Neurosci, 11: 2697-2710.

Swain, J. E., Lorberbaum, J. P., Kose, S., \& Strathearn, L. (2007). Brain basis of early parentinfant interactions: psychology, physiology, and in vivo functional neuroimaging studies. Journal of child psychology and psychiatry, 48(3-4), 262-287. 
Symonds, M.E.\& Lomax, M.A. (1992).Maternal and environmental influences on thermoregulation in the neonate. Proceedings of the Nutrition Society 51,165-172 88.

Szymusiak R, Satinoff E (1981) Maximal REM sleep time defines a narrower thermoneutral zone than does minimal metabolic rate. Physiol Behav 26:687-690

Szymusiak, R., Alam, N., \& McGinty, D. (2000). Discharge patterns of neurons in cholinergic regions of the basal forebrain during waking and sleep. Behavioural brain research, 115(2), 171-182.

Szymusiak, R., Satinoff, E., Schallert, T., Whishaw, I. Q. (1980). Brief skin temperature changes towards thermoneutrality trigger REM in rats. Physiology \& behavior, 252), 305-311

Tadros, M. A., Lim, R., Hughes, D. I., Brichta, A. M., \& Callister, R. J. (2015). Electrical maturation of spinal neurons in the human fetus: comparison of ventral and dorsal horn. Journal of neurophysiology, 114(5), 2661-2671.

Terasawa, F., Yokoyama, Y., \& Kitamura, M. (1999). Rectal temperatures before and after parturition in bottlenose dolphins. Zoo Biology: Published in affiliation with the American Zoo and Aquarium Association, 18(2), 153-156.

Terrien, J., Perret, M., \& Aujard, F. (2011). Behavioral thermoregulation in mammals: a review. Front Biosci, 16(4), 1428-1444.

Tiriac, A., Sokoloff, G., \& Blumberg, M. S. (2015). Myoclonic twitching and sleep-dependent plasticity in the developing sensorimotor system. Current sleep medicine reports, 1(1), 74-79.

Tisdale, R. K., Vyssotski, A. L., Lesku, J. A., \& Rattenborg, N. C. (2017). Sleep-Related Electrophysiology and Behavior of Tinamous Eudromia elegans): Tinamous Do Not Sleep Like Ostriches. Brain, behavior and evolution, 894), 249-261.

Tosini, G., \& Avery, R. (1993). Intraspecific variation in lizard thermoregulatory set points: a thermographic study in Podarcis muralis. Journal of Thermal Biology, 18(1), 19-23.

Tosini, G., \& Avery, R. (1996). Photoperiod affects thermoregulatory set point temperatures in the wall lizard Podarcis muralis. Amphibia-Reptilia, 17(1), 86-88.

Tosini, G., Jones, S., \& Avery, R. (1995). Infra-red irradiance and set point temperatures in behaviourally thermoregulating lacertid lizards. Journal of thermal biology, 20(6), 497503.

Trillmich, Fritz (1990) The behavioral ecology of maternal effort in fur seals and sea lions.Behaviour, 114(1), pp. 1-20

Turman Jr, J. E., Chopiuk, N. B., \& Shuler, C. F. (2001). The Krox-20 null mutation differentially affects the development of masticatory muscles. Developmental neuroscience, 23(2), 113-121.

Ungurean, G., \& Rattenborg, N. C. (2018). Neuroethology: Fur Seals Don't Lose Sleep over REM Lost at Sea. Current Biology, 28(12), R699-R701. 
Valatx, J. L., Jouvet, D., \& Jouvet, M. (1964). A. Chaton intact. Electroencephalography and Clinical Neurophysiology, 17, 218-233.

Van Den Heuvel, C. J., Noone, J. T., Lushington, K., \& Dawson, D. (1998). Changes in sleepiness and BTprecede nocturnal sleep onset: evidence from a polysomnographic study in young men. Journal of sleep research, 7(3), 159-166.

Van Someren, E. J. (2004). Sleep propensity is modulated by circadian and behavior-induced changes in cutaneous temperature. Journal of Thermal Biology, 29(7-8), 437-444.

Vanderwolf, C. H. (1988). Cerebral activity and behavior: control by central cholinergic and serotonergic systems. In International review of neurobiology 30, 225-340. Academic Press.

Vecchierini, M. F., André, M., \& d'Allest, A. M. (2007). Normal EEG of premature infants born between 24 and 30 weeks gestational age: terminology, definitions and maturation aspects. Neurophysiologie Clinique/Clinical Neurophysiology, 37(5), 311-323.

Vergne, A. L., \& Mathevon, N. (2008). Crocodile egg sounds signal hatching time. Current Biology, 18, 513-514.

Vergne, A. L., Aubin, T., Martin, S., \& Mathevon, N. (2012). Acoustic communication in crocodilians: information encoding and species specificity of juvenile calls. Animal cognition, 156), 1095-1109.

Vergne, A. L., Pritz, M. B., \& Mathevon, N. (2009). Acoustic communication in crocodilians: from behaviour to brain. Biological Reviews, 843), 391-411.

Verzijl, H. T., van der Zwaag, B., Cruysberg, J. R., \& Padberg, G. W. (2003). Möbius syndrome redefined: a syndrome of rhombencephalic maldevelopment. Neurology, 61(3), 327333.

Vetrivelan, R., Fuller, P. M., Tong, Q., \& Lu, J. (2009). Medullary circuitry regulating rapid eye movement sleep and motor atonia. Journal of Neuroscience, 29(29), 9361-9369.

Vogel, G. W. (1975). A review of REM sleep deprivation. Archives of General Psychiatry, 32(6), 749-761.

Voigt, W. G. (1975). Heating and cooling rates and their effects upon heart rate and subcutaneous temperatures in the desert tortoise, Gopherus agassizii. Comparative Biochemistry and Physiology Part A: Physiology, 52(3), 527-531.

Von Bartheld, C. S. (2004). The terminal nerve and its relation with extrabulbar "olfactory" projections: lessons from lampreys and lungfishes. Microscopy research and technique, 65(1-2), 13-24.

Vyazovskiy, V. V., Olcese, U., Lazimy, Y. M., Faraguna, U., Esser, S. K., Williams, J. C., ... \& Tononi, G. (2009). Cortical firing and sleep homeostasis. Neuron, 63(6), 865-878.

Wahlberg, Magnus, Lara Delgado-García, and Jakob H. Kristensen. (2017) "Precocious hearing in harbour porpoise neonates." Journal of Comparative Physiology A 203.2: 121-132. 
Walls, G. L. (1942). The vertebrate eye and its adaptive radiation. Cranbrook Institute of Science.

Walter, L. M., Tamanyan, K., Weichard, A. J., Biggs, S. N., Davey, M. J., Nixon, G. M., \& Horne, R. S. (2019). Age and autonomic control, but not cerebral oxygenation, are significant determinants of EEG spectral power in children. Sleep, 42(9), zsz118.

Weber, F., Chung, S., Beier, K. T., Xu, M., Luo, L., \& Dan, Y. (2015). Control of REM sleep by ventral medulla GABAergic neurons. Nature, 526(7573), 435-438.

Weber, F., Do, J. P. H., Chung, S., Beier, K. T., Bikov, M., Doost, M. S., \& Dan, Y. (2018). Regulation of REM and Non-REM sleep by periaqueductal GABAergic neurons. Nature communications, 9(1), 1-13.

Whitten, T. A., Martz, L. J., Guico, A., Gervais, N., \& Dickson, C. T. (2009). Heat synch: interand independence of body-temperature fluctuations and brain-state alternations in urethane-anesthetized rats. Journal of neurophysiology, 102(3), 1647-1656.

WHO, (1997) Thermal Protection of the Newborn: a Practical Guide. Maternal health and safe motherhood programme (WHO/FHE/MSM/97.2): Geneva,

Wikler, A. (1952). Pharmacologic dissociation of behavior and EEG "sleep patterns" in dogs: morphine, N-allylnormorphine, and atropine. Proceedings of the Society for Experimental Biology and Medicine, 79(2), 261-265.

Williams, D. C., Aleman, M., Holliday, T. A., Fletcher, D. J., Tharp, B., Kass, P. H., ... \& Lecouteur, R. A. (2008). Qualitative and quantitative characteristics of the electroencephalogram in normal horses during spontaneous drowsiness and sleep. Journal of veterinary internal medicine, 22(3), 630-638.

Williams, G. C. (1966/2018). Adaptation and natural selection: A critique of some current evolutionary thought (Vol. 75). Princeton university press.

Withers, P. C., \& Campbell, J. D. (1985). Effects of environmental cost on thermoregulation in the desert iguana. Physiological Zoology, 58(3), 329-339.

Wöhr, M., Oddi, D., D'Amato, F. R. (2010). Effect of altricial pup ultrasonic vocalization on maternal behavior. In Handbook of behavioral neuroscience Vol. 19, pp. 159-166). Elsevier.

Wood, C.\& Beard, R.W. (1964). Temperature of the human foetus. Journal of Obstetrics and Gynecology71,768-769.

Woods, J. W. (1964). Behavior of chronic decerebrate rats. Journal of Neurophysiology, 27(4), 635-644.

Wright Jr, K. P., Lowry, C. A., \& LeBourgeois, M. K. (2012). Circadian and wakefulness-sleep modulation of cognition in humans. Frontiers in molecular neuroscience, 5, 50.

Wu, M. F., Mallick, B. N., \& Siegel, J. M. (1989). Lateral geniculate spikes, muscle atonia and startle response elicited by auditory stimuli as a function of stimulus parameters and arousal state. Brain research, 499(1), 7-17. 
Wu, M.F.; Siegel, J.M. (1990) Facilitation of the acoustic startle reflex by pontogeniculooccipital waves: effects of PCPA. Brain Research 532, 237-241.

Wu, Y., Wang, H., \& Hadly, E. A. (2017). Invasion of ancestral mammals into dim-light environments inferred from adaptive evolution of the phototransduction genes. Scientific reports, 7, 46542.

Wurts, S. W., \& Edgar, D. M. (2000). Circadian and homeostatic control of rapid eye movement (REM) sleep: promotion of REM tendency by the suprachiasmatic nucleus. Journal of Neuroscience, 20(11), 4300-4310.

Zepelin, H., Siegel, J. M., \& Tobler, I. (1994). Mammalian sleep. In: Kryger MH, Roth T, Dement WC, editors. Principles and Practice of Sleep Medicine. 4th ed. Philadelphia: WB Saunders, pp 91-100. (2005). 